THEORIA ET HISTORIA SCIENTIARUM, VOL. VI, N ${ }^{\circ} 1$

Ed. Nicolas Copernicus University 2002

Robert E. Haskell

\title{
Cognitive Science and the Origin of Lexical Metaphor: A Neurofunctional Shift (NFS) Hypothesis
}

\begin{abstract}
A long-standing and cardinal issue in the cognitive science and humanities research literatures on lexical metaphor is whether figurative language is derived from literal language. In examining this issue, research from a broad spectrum of studies in both cognitive science and the humanities is addressed with particular attention to findings from classicist research on ancient Greek texts, on the cognitive significance of the invention of the Crreek vocalic alphabet. These findings are related to current research on brain hemispheric laterality. It will be suggested that lexical metaphor was originally not a linguistic figure-of speech derived from literal language but only later came to be so conceptualized as the consequence of a neurofunctional shift (NFS) in hemispheric laterality, a shift that was precipitated in part by the invention and adoption of the Crreek vocalic alphabet. It will be further suggested that the prevailing view of metaphor as a linguistic figure of speech is the consequence of an inappropriate cognitive turn that resulted in a superimposition or back scanning of a modern alphabetic-based epistemology on to phenomena originating in a preliterate culture.
\end{abstract}

Metaphor has long been a subject of inquiry by investigators in the humanities Black, 1962; Richards, 1936; Ricoeur, 1975; Shibles, 1971; Turbayne, 1963; Wheelright, 1962), in psychology (Anderson, 1964; Bornstein and Marks, 1987; Haskell, 1987; Honeck and Hoffinan, 1980; Leary 1994; MacCormac, 19 85). Pollio, Smith and Pollio, 1990; Shanon,1988), in anthropoloogy, (Crocker and Sapir, 1977; Fernandez, 1991), in communications (Reinsch, 1971; Osborn, 1967), and in the natural sciences (Dreistadt,1968). Its systematic lexical analysis goes back at least to Aristotle's (384-322 B.C) work on rhetoric and poetics (Baldwin, 1959; Cooper, 1960). Perhaps few other concepts have been the subject of such 
debate over its definition and function. Traditionally, metaphor has been considered a simple figure of speech where a word or phrase ordinarily designating one thing is used by explicit comparison to designate another, e.g., an "emotional 'storm' ". In addition, the term metaphor itself is used metaphorically to mean symbolic in the sense of a sign that represents something else by an association, or more notably as representing something invisible as in pointing to unconscious ideation. Then there is metaphor's twin, simile, and arguably it's half sibling, analogy as well as its cousins allegory, parable, and proverb. Indeed, the concept of metaphor has become so polysemous as to be nearly omnimeaningful*.

The historical and cardinal issue in the research on figurative language is whether it is derived from literal language, or whether poetics came before prose. Prima faci, this issue may seem naive. But the controversy is one of the most fundamental epistemological issues in the investigation of figurative language. In the humanities, poets (see Boon, 1972) and some philosophers have long maintained that language was originally poetic. Writing in the early part of the seventeen hundreds, the Italian philosopher Giambattista Vico developed a theory on the origin of metaphor and the subsequent metaphorical basis of language (see Danesi, 1995, 1993; Haskell, 1993; 1987b). According to Vico (1948), the first peoples with language "were poets who spoke in poetic characters...formed by their imagination" (p.34). Jean Jacques Rousseau (1966), too, writing in the last half of the seventeen hundreds also thought that language was originally poetic or metaphorical. More recently, the thesis can be found in the controversial work of psychologist Julian Jaynes (1976) ${ }^{12}$ who, like Vico, concluded that "in a certain period of history [people], usually or perhaps

1 A problem with research on metaphor is the lack of agreement on what constitutes a "metaphor". As Anaki, Faust, and Kravetz (1998) note, this is a major theoretical stumbling block in the literature. Indeed, this issue may account for discrepant fmdings and inconsistencies in the literature as well as some of the inconsistencies in the literature cited in this paper. See Pollio, Smith and Pollio (1990) for an overview of some of the issues on the definition problem. It has always seemed clear to me that the multiple manifestations of what are called metaphor are the various instantiations of a more basic neurological substrate(s) generating transformation of invariance, with linguistic metaphor a rather minor instantiation (see Haskell, 1989). In terms of unconscious metaphor, and what I have termed subliteral meaning see (Haskell, In press; 1999) See endnote \# 27. For purposes of this paper, however, the definition of metaphor will have to remain a primitive term.

2 In psychology, a notable exception of the use of data and methods from what has been traditionally considered the province of the humanities is the late Julian Jaynes'(1976a,1976b) controversial thesis on The Origin of Consciousness and the Breakdown of the Bicameral Mind, which has received wildly mixed reviews, though more positive ones from the humanities than from the behavioral and natural sciences. This paper will not address whether Jaynes' entire thesis is valid. As Jaynes points out in the Afterword of the second edition of his book published in 1990, his work contains four hypotheses, not one. I suggest that Jaynes's theory is controversial not only because of his conclusions but because he utilizes what is traditionally thought of as data not 
always spoke in verse" (p. 361; see also Haskell, 1987b)**3. Understandably, this poetic origin of language view has been considered rather quaint, if not bizarre, by linguistic and cognitive science researchers. Only recently has the thesis that all language is essentially figurative been systemically developed in the field of cognitive linguistics by Lakoff (1987), Lakoff and Johnson (1980), though not in the cognitive sense to be developed here.

While the history of metaphor has, and largely remains, tied to its literal linguistic figureof speech heritage (e.g. Ortony, 1979), in recent years it has come to be seen not merely as a simple lexical transfer but as reflecting a deeper cognitive function (Haskell, 1987; Johnson, and Malgady, 1980; Lakoff and Johnson, 1980; MacCormac, 1985). It is this cognitive function subserving what is called lexical metaphor that this paper will attempt to historically trace to its linguistic and cognitive origins.

It will be suggested that metaphor was originally not a linguistic figure-of speech derived \&om literal language but only later came to be so conceptualized as the consequence of a neurofunctional shift (NFS) in hemispheric laterality ${ }^{4}$,

appropriate for cognirive psychology, for example the textual and linguistic analysis of the ancient Greek classics, the Iliad and Odyssey, as well as archeological, and palentological artefacts. Though Jaynes has been given considerable attention by the popular press and humanities literature, it should be noted that serious symposia and publications (e.g., Witelson and Kristofferson, 1986) have also addressed his thesis

3 There is an important issue involved in Jaynes' theory relating to the history of science and ideas as well as to this paper - which I feel compelled to address. Jaynes' thesis has not been only legitimately critiqued but often maligned. For example, one wonders why one author (de Kerckhove 1986) felt it necessary to briefly cite Jaynes, then note that a colleague of his said that Jaynes' works "is not sufficiently scientific to warrant consideration"(p. 276). I suggest, albeit anecdotally that though Jaynes' is seldom formally cited in cognitive science, an exception being Steven Pinker (1997) who briefly cites him, Jaynes' work has nevertheless likely influenced some mainstream researchers. One wonders, too, why the Nobel Laureate, Gerald Edelman (1989) includes Jaynes in the primary references of his book but not in the index. Likewise the neuroscientist Joseph LeDoux (1996) includes Jaynes in the primary references but not in the book index. Two other books by respected researchers come to mind. Perhaps coincidentally, in the first (Gazzaniga, 1985), Jaynes' influence seems clearly evident. The book addresses many of the issues that Jaynes does, and uses similar kinds of data. For example, the question of prehistoric evidence on the nature of thought in the human species and especially the question of whether religiosity is hardwired into the brain. Jaynes is not cited. In the second book (Omstein, 1997), the author addresses similar issues (as can be seen in this paper) using similar data without so much as a passing reference to Jaynes, though many of the same authors are cited, authors that are rarely referenced in mainstream psychology, i.e., Eric Havelock (1963) the classicist scholar. In any event, lacking the time and space to develop this observation systematically, the reader is invited to read these two books concurrently with Jaynes (1976) book.

${ }^{4}$ Because the complex findings on hemispheric asymmetry have become so popularized into oversimplified claims, whenever I refer to LH and RH I mean a complex of associated functions. However, instead of repetitiously using the term "associated", I will often omit it. 
a shift precipitated by the invention and adoption of the Greek vocalic alphabet sometime around 900 BC. It will be further suggested that the prevailing view of metaphor as a linguistic figure of speech is the result of an inappropriate superimposition or back scanning of a modern alphabetic-based epistemology on to its preliterate origins.

Due to the number of interdisciplinary areas that will subserve this initial formulation of the NFS hypothesis, it is only possible here to summarize the complex - and equally important, converging - material. For the same reasons, the NFS hypothesis can not be presented as concisely and straightforward as is typically expected: In science, uncommon hypotheses call for uncommon justifications. The purpose of this paper in presenting a NFS hypothesis, then, is not so much to present a detailed account of the origin of lexical metaphor as it is a to broadly sketch an array of data with which to develop a framework for stimulating further inquiry, research, and theory.

\section{Initial Statement of the NFS Hypothesis}

It has always been accepted in Western culture that the flowering of rationality and scientific thinking began with the Greeks, and further, that it was a unique event occurring around $500 \mathrm{BC}$. The question is: What precipitated this ancient Renaissance ${ }^{5}$. One answer is that the invention of the vocalic alphabet by the Greeks somewhere around $900 \mathrm{BC}$ initiated this renaissance. The historical data and evidence that applies to this answer comes from research by classicists in the humanities (Havelock, 1986, 1983,1963; Parry, 1971; Snell, 1953) on the analysis of Greek texts; more specifically the Iliad and the Odyssey of Homer and to a lesser extent the Theogony of Hesiod ${ }^{6}$.

In summary form, the controversy revolves around a number of issues: that the Iliad and the Odyssey (1) are not poetry but "literal" narratives, (2) originated from an ancient Greek oral tradition, (3) are thus oral "documents" or narratives, which (4) were transcribed into their written form sometime during the initial inception of the Greek vocalic alphabet, and therefore (5) the Greek vocalic alphabet, because of its virtual oneto-one correspondence of sound to each letter, unlike previous pictographic and cuneiform writing, affected the organization of the brain, hence (6) these ancient documents reflect a cognitive shift which led

${ }^{5}$ While the Greek renaissance occurred during what has been called an Axial Age (Eisenstadt. 1986) where a number of major civilizations were experiencing revolutions in ideas and institutions, the Greek revolution is considered by many to nevertheless to be unique (See, Machinist, 1986).

${ }^{6}$ Havelock's thesis of an ancient (Ireek oral tradition and the importance of the invention of the Greek vocalic alphabet is not as controversial as it once was (Robb, 1983). 
modem philosophy and cognitive science to misinterpret ancient writings from a modem literate perspective. While this classicist research does not directly address the issue of metaphorical or figurative language, the implications are clear and will be outlined below.

There are two forms of the NFS hypothesis, each with different implications. The first, or weak form, suggests a more radical shift in consciousness that was initiated by the above changes. This weak form has been claimed by Vico, Rousseau, and Jaynes. The stronger form states that a shift from an oral culture to a vocalic alphabetic/literate culture affected the organization of the brain, more specifically neurological lateralization. This in turn affected language use, more specifically, lexical metaphor. The Thesis of Havelock (1963) generally claiming that there was a pre alphabetic "cast of thought or mental condition" (p.x) could arguably belong to either the weak or strong form of the NFS hypothesis. This paper will address only the stronger form of the NFS hypothesis.

Correlated with what is currently known about cognitive processes and neurological findings, a picture of a pre vocalic alphabetic cognition seems to emerge. This view is important, not only for understanding the origin of metaphor, but because it may reveal new information about cognition that may well be amenable to developing further testable hypotheses and theory construction. In presenting evidence for a NFS hypothesis, this paper will therefore and of necessity initially make use of historical data from the humanities, data that stray from the more traditional data of cognitive science, indeed, from "normal science" methods (see Kuhn, 1970) as they are commonly understood.

\section{Initial Methodological Considerations}

Attempting to investigate cognitive processes three millennia ago requires different methodologies than are currently used by most of cognitive science. Excluding estimates on brain size inferred from cranial capacity, there is, after all, no fossil record of brain tissue. There is, however, a kind of fossil record of cognitive processes to be found in the linguistic structure of ancient Greek documents and other sources - albeit an indirect record. Many scientific fmdings, however, are based on indirect inference from historical evidence, providing a kind of retro data, as it were. For example, astrophysics, palentology, archeology and geology ${ }^{7}$. Accordingly, to reconstruct cognitive and linguistic processes requires using existing related evidence.

${ }^{7}$ A nascent field called cognitive archaeology has recently emerged. See Renfrew and Zubrow (1996). 
In agreement with Chiarello, (1991) and others (Edehnan, 1989; Kosslyn and Koenig, 1995), while cognitive science has achieved considerable success in understanding mind as an abstract information processing and computational system, because it has been abstract and formal, it has tended to lack actual nervous system instantiation, what Kosslyn and Koenig (1995) have termed a "wet mind" perspective. As Chiarello, notes, "the most elegant model of some cognitive process, even if it predicts a range of behavioral data, may not be the right model unless it is also neurologically plausible" (p. 251). Accordingly, the NFS hypothesis will argue for a "wet" view of lexical metaphor, not a "dry" formal linguistic and computational one.

In addition, cognitive science and cognitive psychology research on mind, and consequently on metaphor, has been largely ahistorical. Moreover, cognitive science is founded on research premised on a modern, literacy/alphabetic-based epistemology. From an historical and neurological framework, then, cognitive research constitutes a narrow cross sectional view of mind/brain processes. The question is: have cognitive processes as currently understood always been extant?

What is required to answer this question is a more longitudinal or historical view, a view that must inevitably utilize data from the humanities, an area that both cognitive psychology and cognitive science have not typically considered a valid source of evidence. This is perhaps understandable given the lack of what is considered by cognitive science to constitute rigorous methods. Though certainly not experimental, the study of history, archaeology, palentology, and even some literary criticism methods are rigorously systematic. In any event, cognitive science need not accept data from the humanities as conclusive, but should consider some data as possible fertile sources of hypotheses, and selectively as corroborating data. Conversely, the humanities could more instructively utilize findings fiom cognitive science ${ }^{8}$.

At least since C. P. Snow's now well-known observation on the split between the "Two Cultures", one the sciences and the other the humanities, the importance of rectifying this split has been widely agreed upon-in the abstract. With few exceptions (e.g., Simon, 1994), however - at least in the sciences - follow-through has been largely absent, as a recent review of the issue indicates (Snow and Collini, 1999). It is pertinent to note that the methodology used by humanities researchers is often the analysis of both ancient and more modern narratives or texts. The use of narratives to study human behavior is not restricted to the humanities, however, but has been used for some time in anthropology (e.g.,

${ }^{8}$ The separation of the "Two Cultures" tends, like much ethnic prejudice to result in misinformation about the other. For example, many, perhaps most of my colleagues in the humanities think psychology is Freudian; indeed, the humanities literature is well known for largely citing Freud when explaining something in their field psychologically. 
Goody, 1977; Levi-Strauss, 1966). Though not typically used in cognitive science and psychology, the analysis of narratives for investigating cognitive processes has occasionally been used (e.g., Thorndyke, 1977), both Bruner (1990) and Simon, (1994) have emphasized the value for cognitive psychology of using narrative data, more specifically oral narratives ${ }^{9}$.

\section{The Cognitive Turn}

Aristotle developed his philosophy hundreds of years after the adoption of the Greek vocalic alphabet had became interiorized. Hence Western philosophy inherited Aristotle's post oral age literacy-derived philosophy. It is with Aristotle, then, that the modern view of metaphor as a figure of speech, as a deviation from literal meaning seems to have originated. The NFS hypothesis states that the modern historical view of metaphor as a linguistic figure of speech is the consequence of an inappropriate superimposition or back scanning from a modem literate (vocalic alphabetic-based) cognitive tradition, along with its ensuing epistemology distorting the investigation, understanding, and interpretation of non literate phenomena and data - in this case, lexical metaphor. If this hypothesis is correct, then as Lakoff (1987) has noted in the context of the literal/figurative controversy, "We are at present at an important turning point in the history of the study of the mind. It is vital that the mistaken views of the mind that have been with us for two thousand years be corrected" (p. xvi). While Lakoff does not suggest a NFS, his point is that cognitive researchers are interpreting linguistic phenomena from an Aristotelian bias and engaging in a kind of revisionist history, as it were, regarding figurative language. In noting the same bias, Le Doux, 1996) says, "Cognitive science resurrected the Greek idea of mind, mind as reason and logic. And because the kind of mental states that were being suggested in the earlier days were based on the rules of logic, which is closely tied up with the human capacity for language... The idea of the human mind as a carefully engineered machine seemed more appealing than the idea of the mind as a biological organ with an evolutionary history" (p. 39). Haskell (1987b) suggested a similar Aristotelian bias in interpreting the work of Vico, as does Havelock 1963) in interpreting the work of Plato ${ }^{10}$. Vico (1948) was acutely aware of

${ }^{9}$ Even when oral narrative data are transcribed and used in psychology, they are ahnost invariably analyzed as if they were written documents, not as the oral data they in fact constitute.

${ }^{10}$ Havelock (1963) argues that Plato has been misinterpreted throughout the history of Western philosophy. For example, in his Republic Plato rails against poets. According to Havelock, understanding that Homer's work was an oral encyclopedia that the Greeks used as instruction and poetry as we think of it, makes Plato's views against poets a different argument. On this view, 
what he called the "conceit" of scholars "who will have it that what they know is as old as the world" (p. 19, italic added). It is in Vico's sense, then, that this paper refers to a cognitive turn, an epistemological turn that twisted metaphor into a linguistic devise.

Parry (1971b), the classicist who demonstrated that the works of Homer were in fact originally works fcom an oral culture (see below), says, "Aristotle did not understand [that]... between the final vanishing of the old oral poetry and his own time two hundred years or more had already passed, and, thinking of Homer as he thought of the epic poetry of his own age, he failed to see that the metaphor was one thing for Antimachus and another for Homer". Parry continues,

„Homer's traditional diction is the work of a way of life which we may call the heroic, if one will give that word all the meaning it had for the men of Homer's time. It is a term which can only be understood in the measure that one can think and feel as they did... to give form to this heroic cast of thought they had the old tales that had come down in time, and they had a rhythm in which to tell them, and words and phrases with which to tell them" (p. 374) ${ }^{11}$.

Beginning with Aristotle, then, is perhaps found the initial turn to the modern view of metaphor as a figure of speech.

In psychology and cognitive science, this epistemological turn - but more importantly the significance of the Greek vocalic alphabet on cognitive processes - is virtually unrecognized, with two exceptions. The first is Jaynes (1976), the second Ornstein, (1997). Recognizing the work of Havelock (1963) and others, Ornstein says, "We are heirs to the Greek intellectual tradition, one of single-file logic and rational analysis. And it is not only the formal arguments of Aristotle that have been passed down, it is the alphabet itself including its vowel sounds and the way we write it, from left to right, that may play an unexpected role in our brain organization" (p. 39). He continues,

"A mental revolution happened in the left hemisphere when an alphabetic, full- context language was set, through left-to-right writing. The left side of the brain was already specialized to act sequentially... The change in writing became the means

the so-call poetry that Plato reacted against was not poetry in the modern sense but the use of the old Homeric type verse to educate the young.

" It is interesting to compare Parry (1971c): He say the language of Homer was "heroic, if one will give that word all the meaning it had for the men of Homer's time. It is a terxn which can only be understood in the measure that one can think and feel as they did", (p. 374) with Vico (1948): "the heroic language which was spoken at the time (p. 4) ...It is equally beyond our power to enter into the vast imagination of those first men, (p. 76). Even more interesting are the many similarities between Vico and Jaynes (see Haskell, 1993). 
of introducing a new state of mind - what historian Ernest [sic] Havelock has called "the alphabetic mind... So, the development, after millennia of learning to write in a completely abstract way of representing the world fits in well to the already existing side preference of the brain. It was a glorious accident, but it led to our learning about the world in symbols and, changing the way our brain worked" (p. 39, italics added).

Thus, the invention and subsequent influence of the vocalic alphabet lead to an Aristotelian linear logic and rational sequential form of argument.

In discussing the differences between oral and literate cultures, de Kerckhove (1986) has suggested that "the interpretation of cultural differences and historical developments may require a paradigmatic shift in scientific and scholarly investigations" (p. 291). As indicted at the opening of this paper, some researchers in the humanities (Havelock, 1963, 1983,1986; Ong, 1982) have suggested that the invention of the Greek vocalic alphabet and the subsequent shift to a left-to- right writing resulted in a shift in "consciousness". In addition, both de Kerckhove (1986) and Skoyles (1988) have suggested a change from what they hypothesize to have been a RH (reading) literacy in ancient Greece prior to the invention of the vocalic alphabet to a modern LH literacy ${ }^{12}$.

Understanding the significance of the Greek vocalic alphabet, de Kerckhove (1986) correctly contends, "an important contribution can be made to cognitive and neuroscience if it can be shown that certain features in orthographies such as alphabetic signs and the direction of writing are related to neurological lateralization" (p. 275). It is suggested here that - in part - this orthographic change led to a NFS and subsequent cognitive turn generated the literal $\mathrm{v}$. figurative dichotomy that has dominated metaphor research for over two thousand years.

\section{Literal-Figurative Issue}

Two current research perspectives reflect the literal vs. figurative language controversy. The first is exemplified by MacC"ormac (1985) who essentially maintains a literalist stance, the second by Lakoff (1987) and Lakoff and Johnson (1980) who maintain all language is ,at its base, metaphorical (though not in the NFS sense being suggested here). To reproduce the details of this debate would neither be appropriate nor pertinent as the NFS hypothesis of

${ }^{12}$ I would like to acknowledge a debt to the work of John Skoyles. As I was in the middle of writing this paper I came across his publications on the RH reading literature that I cite here, as well as some other reference, for example de Kerckhove's work. 
this paper circumvents much of the debate. By way of introduction to the main arguments of this paper, however, it is instructive to look briefly at the basic framework of Lakoff and Johnson (1980) and extended by Lakoff (1987). They demonstrate that most of what we call literal language can be seen as simply dead metaphors, as in the phrases, "time flies, " the "foot" of a mountain, or the "leg" of a table. Their view is that such obvious metaphors like the "legs" of a table referring to the four vertical pieces of wood that hold a table upright are obviously not "real" legs (as in human appendages to which fleshy feet with toes are attached). As they explicate in detail, even our sense of time is based on a spatial metaphor with events happening "before" or "prior to", etc. (see also Turbayne, 1963).

Lakoff and Johnson maintain that such phrases have become "literal metaphors"; or what they call "conventionally fixed" metaphors. After an extensive analysis of seemingly literal language, they claim that these examples are paradigmatic of the metaphorical nature of language. Though their claim is not a novel one, either in the humanities or in the long history of the literature on metaphor, what Lakoff and Johnson have accomplished is the legitimization of the issue and bringing it into cognitive science and linguistics. More importantly, however, they have gathered, analyzed, and otherwise brought together the linguistic, logical, poetic, philosophical, and epistemological arguments in the literature on the literal/figurative debate and have developed a systematic and coherent framework/theory in which to understand-and perhaps begin to resolve - the debate.

If the cognitive linguistic thesis of Lakoff and Johnson stating that most, if not all, current literal language is simply conventionally fixed metaphors is accepted, then a radical implication is that at some point in history language was largely if not exclusively metaphorical. After all, how would metaphors become dead, fixed and conventional if they were not first live and poetic? The question is, is it scientifically possible to examine and fmd evidence for a phenomenon that, if it did exist at some point in history, no longer does? To address this issue requires more than the cross sectional analysis and methods of cognitive science. Answering this question requires an historical approach.

It has been suggested here that one place to look for evidence of a language that was primarily metaphorical or figurative is in the works of the ancient Greek "poet" Homer in his Iliad and Odyssey. This is not a place where traditional cognitive science has gone for evidence before. As indicated in the opening of this paper, it is in the shift from an ancient Greek oral culture to a vocalic alphabetic/literate one that there exists possible evidence bearing on the thesis that language was originally "poetic", figurative or metaphoric. To begin to examine this evidence requires examining what is called the Homeric Problem. 


\section{The Homeric Problem and the Literal Figurative Issue}

The Homeric problem, is a long standing one in the humanities ${ }^{13}$. The problem to be addressed is that the ancient Greek classics, the Iliad and the Odyssey, long considered to be great poetry may not in fact be poetry at all in the modern literate sense, but are instead historical oral "documents" based in an ancient Greek oral tradition. Most classicists who maintain the orality thesis suggest that these "poems" were orally composed around 950 B.C. and were handed down by oral transmission until around the sixth century B.C. when the Greek vocalic alphabet came into general use, at which time they were written down.

While this thesis has been around for centuries in one form or another, it was Milman Parry (1971), considered one of the leading classical scholars of his time ${ }^{14}$, who in the late 1920s and early 1930s documented that the language in the Iliad and the Odyssey was the consequence of the memory demands imposed on lengthy oral recitation and not poetic in the modem sense. He showed that repeated formulae were mnemonic devices imposed on an oral mode of remembering large stores of information. As Havelock (1963) also later argued, these "poems" were the work of bards or aoidoi whose function in an oral age was to be a kind of living encyclopedia that encapsulated, preserved, and passed down the knowledge of the culture.

According to Parry, the basic mnemonic technique was to create structural formulas, groups of words for dealing with traditional materials. Each formula was constructed to fit into a hexameter line. The Bards or "poets" had a massive vocabulary and store of hexameterized phrases with which to fabricate correct metrical lines without end as long as they dealt with traditional materials. Originality in these "poems" consists not of novel materials but of fitting new situation into traditional material by the use of formulaic structures and phrasings. Ong (1982) comments that, "Parry’s discovery might be put this way: virtually every distinctive feature of Homeric poetry is due to the economy enforced on it by oral methods of composition" (p. 21) due to memory limitations. Further, it is

13 The Homeric Problem is really two problems. The first problem involves whether the ancient Greek poet known as Homer is in fact the author of the Iliad and Odyssey. There is considerable consensus now that it is likely the Iliad and the Odyssey are not the work on one person, but the work of a number of aoidoi or "poets" who at the dawn of the invention of the Greek vocalic alphabet wrote down works that originated in an oral society.

14 Adam Parry (1971) - the son of Milman Parry - cites a well-known scholar who says that "the proofs offered by Milman Parry are of a quality not often to be found in literary studies" (p. xxvii). 
believed that these "poems" were originally created and delivered by minstrels in a kind of melodic, singing - like cadence.This too, facilitated memory for the massive amount of material the minstrel was required to master. Subsequent research on contemporary oral cultures have shown the same formulaic structures and melodic delivery by singing minstrels (see, Parry, 1971 ). Many classicists generally accept this orality thesis.

Thus, as narrative data, these ancient Crreek documents can be analyzed linguistically and cognitively. In doing so, they may reveal aspects of different cognitive processes than that created by modern literacy. Along with Havelock, (1963) and Snell, (1973), Jaynes' (1976) says of the Iliad, "I propose here to regard the poem as a psychological document of immense importance" (p. 69) ${ }^{13}$. Virtually no mention is made, however, in cognitive science literature of the Homeric Problem or of Parry's work in specific on the nature of metaphor in these classic narratives. Nor has the humanities addressed the issue of metaphor, either in relation to the Homeric Problem in general or to Parry's work. Despite traditional research in the metaphor literatures not addressing these data, it is in these narratives that we may begin to find the first clues to the origin of lexical metaphor and to a resolution of the literal/figurative controversy.

In two brief papers, Parry (1971 a, 1971b) specifically addresses the issue of metaphor as found in Homer. Using systematic textual and linguistic analysis of these narratives, Parry demonstrated that the vast majority of the "metaphors" are not poetically novel, but cliche-like "figurative" phrases ${ }^{16}$. Thus what seems from a literate perspective to be poetic metaphors are apparently not metaphorical in the novel or "poetic" sense. Words and phrases like: spears yearning to sate themselves on flesh, or a battle quivered with spears, or describing voices as sweeter than honey, or on his tongue they pour sweet dew are used so often in Iliad and the Odyssey that Parry (1971b) considers them what he called "fixed" or "traditional metaphor" (p. 367). Parry's formulation of fixed and traditional metaphor is similar to what Lakoff and others have termed "dead" or "literal metaphor" as it now might be said to "see the point" of an argument, or to "catch" its meaning.

15 It seems the Iliad originated earlier than the Odyssey, and the Odyssey certainly earlier than Heisod's Theogony. Consequently, when they were written down, they increasingly reflected different literate characteristics and therefore decreases in the purity of their oral characteristics. Thus, for purposes of this paper, I will use the Iliad as a kind of shorthand for fmdings from all three documents.

16 One of the cognitive formulas that Parry (1971a) identified in the Iliad is the use of analogical structure which involves " the formation of new formulary expressions on the model of particular words and of the sound-pattern of old formulary expressions which is. Parry argued, the creative force in the formation of the epic style. Its importance in Parry's work has been much overlooked" (p. xxxii). This is what I have elsewhere identified as structural metaphor (Haskell, 1987a). 
It is not entirely clear whether Parry's concept of "fixed", or "traditional metaphor" is made out of the same stuff as what Lakoff and others have called "dead metaphor" or "literal metaphor". It seems they have at least many similarities, both being described as largely figurative cliches from an everyday vernacular ${ }^{17}$. The question now is whether Parry's view, too, of the origin of these metaphors is the consequence of superimposing a literate perspective onto a different and more ancient oral set of cognitive and linguistic processes. In other words, is Parry's calling the Iliadic phrase "a battle quivered with spears" a "fixed metaphor" equivalent to what is considered today a "dead metaphor" like I "catch your drift?" (Either way, the view of the Iliad and the Odyssey not being poetry in the modern literate sense would still be the case). These fixed and traditional metaphors, then - by definition - had their origins in the everyday language and vernacular of the times ${ }^{18}$. So, the crucial question for the NFS hypothesis is this: Were these metaphors that were taken from the daily vernacular typical cliche figurative phrases as we now have in our every day language, or were they drawn from a daily vernacular that was fundamentally poetic or metaphoric?

Etymologically, there is evidence that could support the view of a daily vernacular that was fundamentally poetic. Havelock (1963), Snell (1953) and other classicists in tracing the origin and development of Crreek word meanings have shown that words often grew out of bodily parts and processes that were "metaphorically" applied to non bodily phenomena ${ }^{19}$. For example, Verbs identifying birth and death were applied to anything that was new or created and

17 To explain and further support his claim that the Iliad was made of "fixed" and "traditional metaphors" taken from an everyday language, Parry (1971c) draws a parallel (analogy?) with the "true fixed metaphor" that has not been used, he says, since they existed in English poetry " when Anglo-Saxon was spoken. Nevertheless some idea of its nature can be gotten if we consider the use of metaphor in the English Augustan Age. This was the one time in English literature when poets used a diction which was at all fixed....so that most of the poetry was written in a style whieh largely used the same words and types of phrases, and very often even the same phrases. The verse form also had no small part in this fixation of the poetic diction, since the close form of the heroic couplet often prompted the repeated use of certain types of phrases" (p. 366). Again, was Parry superimposing a literate perspective (analogy?) on the structure of the Iliad!

18 Ong (1982) makes a most interesting point regarding how we perceive with a modern perspective that perhaps parallels the traditional view of the Iliad as poetry instead of oral verse. He says that some modern cultures have had writing for centuries but have not completely interiorized it. For example Arabic which still relies heavily on formulaie thought and expression. The well-known author Kahlil Gibran (1976), observes Ong, has been quite successful providing oral formulary in print to literate Americans who consider his work ,poetic, “ and "proverbial, “ but which apparently citizens of Beirut regard as commonplaces.

19 See Vico (1948) for his theory of metaphor originating from sensory metaphors based on the body and bodily processes. See also Johnson (1987). 
that ended. Evidently, early Greeks had no equivalent of the verb "to be". Indeed, the word soma, which in the fifth century B.C. came to mean body, is used in the plural in Homer and refers concretely to dead limbs or to a corpse. Lacking abstraction, when the body was referred to it was by its parts and never the body as a whole entity. The word psyche, which now means mind, originally referred to bodily processes like blood or breath as in bleeding from ones psyche. The word thumos, later to refer to emotion, later came to mean motion or agitation. Similarly the word phren, which was originally located in the chest and often meant catching one's breath when surprised. Only centuries later did it comes to mean mind or "heart" in the metaphorical sense ${ }^{20}$.

In order for the so-called "fixed metaphors" in the Iliad not to have been cliched metaphorical phrases but rather the product of a predominantly figurative or poetic-like language to make sense, it would suggest that the daily language community was one largely composed of a figurative and poetic-like language (as above). Indeed, Havelock (1983) provides a hint that this may have been the case. In reviewing the writings of the Presocratics, he says,

The initial evidence that they were in pursuit of a new vocabulary, and were aware of the fact, is furnished by the insistent polemic that they all direct against the language currently in use, which they sometimes identify as that spoken by Homer and Hesiod, and other times by men generally (p. 15, italics added).

Thus it seems that some ancients suggested that the everyday language may have been figurative or metaphorical. Is there evidence consistent with such a NFS? Findings from two literatures suggest that there may be such (indirect) evidence. The first is the literature on literacy and reading processes; the second is the neurological laterality literature. Since it has been generally held that language processes are almost exclusively LH dominant and that this dominance is neurologically inherent, it is necessary to preliminarily look at some of the laterality research consistent with a NFS hypothesis.

\footnotetext{
${ }^{20}$ Reviewing this etymological literature, Jaynes (1976) sees its relevance to a theory of metaphor. He says, "It is not always obvious that metaphor has played this all important function. But this is because the concrete metaphors become hidden in phonemic change, leaving the words to exist on their own. Even such an unmetaphorical-sounding word as the verb «to be' was generated from a metaphor. It comes from the Sanskrit bhu, "to grow, or make grow", while the English forms 'am' and 'is, have evolved from the same root as the Sanskrit meaning to breathe". It is something of a lovely surprise that the irregular ar conjugation of our most nondescript verb is thus a record of a time when man had no independent word for 'existence' and could only say that something 'grows' or that it breathes", Of course we are not conscious that the concept of being is thus generated from a metaphor about growing and breathing. Abstract words are ancient coins whose concrete images in the busy give-and-take of talk have worn away with use" (p. 51). This idea of phonemic change obscuring the origin of many metaphors is a significant insight into the development of lexical metaphor.
} 


\section{Preliminary Considerations for Early Influences on Laterality}

Presenting fmdings on cerebral lateralization requires comment because of the popular and wide spread oversimplification of the RH being strictly synthetic, emotional, and intuitive with the LH being analytic, logical, sequential, and hardwired for language. In addition, much of the evidence is based on problematic data from clinical populations, i.e., commissurotomies, stroke patients, etc., with findings often being quite variable. Further, many functions of the two hemispheres are (a) not specialized in absolute but rather in relative terms, as differences in degree, and (b) often duplicated in the two hemispheres, but (c) not equally effective in each hemisphere depending on task requirement and other variables ${ }^{21}$. With this said, it is nevertheless clear that while some aspects of brain lateralization are hard wired, it now also seems increasingly clear not all aspects of laterality are set from birth (Deacon, 1997; Kosslyn and Koenig, 1995; Omstein, 1997; Springer and Deutsch, 1981).

Increasingly, it is being recognized (Best and Avery, 1999; Chernigovskaya, 1994; Deacon, 1997; Galin et al, 1992; Ornstein, 1997; Metcalfe, Funnell, and Gazzaniga, 1995) that the development of certain aspects of lateralization are influenced by the environment. Ornstein (1997) has noted that "It is likely that the culture one encounters at birth and first few years affects the way the hemispheres are organized" (p. 38). Similarly, Deacon observes (1997) that the abilities of the hemispheres, "may be masked by [a] long developmental specialization, which actively reduces its roles in word and phrase-level analysis and production processes in order to avoid cognitive conflicts... Lateralization is not so much an expression of evolutionary adaptation as of adaptation during ones lifetime, biased so as to minimize any neurological "indecisions" about what should go where" (p. 314). In addition to the typical findings on neuroplasticity, where early LH damage in children often leads to a re routing of the language function to the $\mathrm{RH}$, there are other findings as well pointing to environmental influences on lateralization.

Curtiss (1989) cites the well-known - albeit anecdotal - case of Genie, an adolescent who had existed in extreme social deprivation conditions for nearly the first twelve years of life (see Krashen, 1973). Two years after release from confinement, she had made limited progress in learning language (as the authors point out, the language learning fmding is significance for the theoretical issue

${ }^{21}$ Only a couple of apparently anomalous patients have been found who were able both to understand language and to speak from their RH (Gazzaniga, 1992). 
of whether language competence can be fully learned after puberty). Of particular interest, was her performance on tests of dichotic listening. As is typical for most subjects, she was able to identify correctly both familiar words and environmental sounds when tested one ear at a time. However, when the words were presented dichotically (i.e., simultaneously), her performance differed considerably from the typical response. Instead of the moderate LH advantage usually found in right-handed subjects, she showed an extreme RH advantage. Her RH performed perfectly, while the performance of her LH was only at chance level. With environmental sounds. Genie demonstrated a small RH advantage, in keeping with typical findings that such sounds are processed more efficiently in the RH. Being a clinical case study, conclusions drawn from it must be extremely tentative, but it appears that the processing of language and non language stimuli was occurring in Genie's $\mathrm{RH}^{22}$.

There are other studies suggesting environmental influences on the development of laterality, primary among which are studies on the affects of early exposure to a particular language community. Springer and Deutsch (1981) cite the research on socioeconomic class (see Borowy and Goebel, 1976; Dorman, and Geffner, 1974; Geffner and Hochberg, 1971; Zook and Dwyer, 1976) that hemispheric lateralization is influenced by ones experience with a language community. Pretesting for language ability, lower socioeconomic class (LSEC) right-handed children from 4 to 7 years of age were matched for age and sex with middle SEC right handed children and given a dichotic listening test using digits. Results indicated a significant LH superiority in the 4-, 5-, 6-, and 7-year- old children from the middle SEC group, while only the 7-year-olds from the low SEC group showed a LH advantaged. The authors of the study conclude that if these fmdings are interpreted in hemispheric terms, the RH appears to develop similar levels of ability in different enviromnents while development of the LH is depressed by linguistically deprived environments. In another study, a LH advantage was found in both low SEC and middle SEC children, but the middle SEC children showed LH advantages of significantly greater magnitudes. Springer and Deutsch conclude that while SEC differences in ear asymmetry

${ }^{22}$ The investigators working with Genie correctly acknowledge that her left hemisphere may have begun language acquisition before her confinement but through disuse was no longer able to fulfill its original function. As Genie began to learn language a second time, the RH assumed control because its functions had presumably been exercised (by visuo-spatial processes) in spite of her confimement. The problem with a single-subject study such as this is that we have no way of knowing the pattern of asymmetry that would have developed in Genie's brain had she had a normal childhood. Perhaps she would have shown right-hemisphere specialization for language and nonlanguage stimuli anyway. Nevertheless, the results are intriguing, especially in light of work looking at hemispheric asymmetry in the congenitally deaf. 
in ear asymmetry have not been found in all studies, "if the differences are real, they suggest that environmental factors correlated with SEC affect lateralization of function" (p. 142). Thus a NFS having occurred as the consequence of a radical change (literacy) in the environment is not improbable (see more below). Even more primary than degree of language experience - and more specific to subserving the NFS hypothesis of this paper is the affect of literacy and non literacy on hemispheric lateralization ${ }^{23}$.

\section{Language, the Vocalic Alphabet and Laterality}

The primary methods of assessing lateralization of language function are dichotic listening procedures where linguistic sounds are simultaneously and separately transmitted to each ear (Kimura, 1966). Dichotic listening studies seem to have consistently demonstrated that linguistic sounds are perceived more efficiently by the right ear (which connects to the LH). Other methods include testing so- called split brain or commissurotomy subjects where the communication link between the two hemispheres are severed, and the chemical Wada test which anaesthetizes a hemisphere (Wada, and Rasmussen, 1960), as well as research from stroke patients. It is nearly indisputable in the lateralization literature that in most right handed people language proficiency is overwhelmingly restricted to the LH. The claim that there are some linguistic comprehension abilities (as opposed to speech production) in the RH, however, is now less controversial than in the past. Based on their research on brain intact subjects and their review of the research literature, Anaki, Faust and Kravetz (1998), conclude that the accumulated neuropsychological evidence obtained \&om brain-intact, hemispherectomized, commissurotomized and brain-lesioned patients all suggests that the RH possesses distinct linguistic capacities. Ornstein, (1997), too, concludes that the RH seem to possess more language ability than once thought.

From their research Zaidel (1982) and Zaidel and Peters (1981), conclude that when tested separately from the left hemisphere, as can be done in splitbrained individuals, there is a $\mathrm{RH}$ reading capacity. However, they point out that, unlike the $\mathrm{LH}$, the $\mathrm{RH}$ recognizes words visually not phonetically. And Chiarello (1991) found that though the linguistic ability of the LH (of split brain patients) exceeded that of the RH, the RH "had at least rudimentary lexical- semantic capacities" (p. 253), concluding that the human brain consists of two linguistic semantic systems, not one.

\footnotetext{
${ }^{23}$ The term non literacy is use here in contradistinction to illiteracy, where the latter term is often used interchangeably with degree of literacy. Illiteracy is used here in its strict sense of no experience of alphabetic reading or writing.
} 
Moreover, the prevailing view that the capacity for language per se is inherent or hardwired in the LH may be a confound on two levels. In addition to being possibly confounded with vocalic alphabet/literacy affects, it has been suggested (Kimura and Archibald, 1974) and is increasingly being seriously considered by others (Chiarello, 1991; Edelman, 1989; Kosslyn and Koenig, 1995; Springer and Deutsch 1981) that LH capacity for language is not for language per se, but an adaptation on the already existing complex set of motor manipulation abilities. This motor manipulation ability involving sequencing is thought to be translated into grammatical/syntactical functions when the phonetic sequencing of language is imposed on it. de Kerckhove, (1986) notes that some neurobiologists (e.g., Changeux, 1983; Krashen, 1975; Kinsbourne and Lempert, 1979; Nebes, 1975;) maintain that

speech finds its place in the left hemisphere, not ontogenetically, but because the left brain's timing processes reflect and accommodate the serial nature of the production and the reception of linguistic sounds. If that is indeed the case, it can also be suggested that the adoption of vocalized alphabet may have more than any other system promoted and reinforced reliance of left hemispheric strategies" (p. 288, italics added).

More importantly, both Skoyles (1988) and de Kerckhove (1986) point out that current knowledge of brain lateralization is largely based on readers of modem European phonetic alphabets. As Skoyles, notes in reviewing the literature on a RH reading, especially with pictographic scripts, that "One should not assume that the neurological processes of modern reading, including lateralization, existed in a similar form in earlier times", (p. 364, italics added).

Prior to the invention of the Greek vocalic alphabet there was, of course, writing. The difference, however, was that writing was characterized by pictographic script like hieroglyphics and by the Sumerian cuneiform, a graphic script characterized by small wedge-shaped elements. As suggested above, the RH is more specialized for visuospatial phenomena (like pictographic script) than is the LH. While it is not possible in this paper to reproduce the complex body of evidence and arguments supporting the differences in and the shift from an oral and pictographic based culture to a vocalic alphabetic one, the essential overview based on the above authors (de Kerckhove, 1986; Havelock, 1983, 1986, 1963; Skoyles, 1988, 1984), is as follows.

The reason for the superiority of a vocalic alphabet is that prior to its invention reading was with pictographic type scripts which were often read and written either vertically or from right to left - as in modem Arabic and Hebrew. The phonetic aspects were characterized by mostly consonants and some semi vowels attached to the script, which when the Crreeks added systematic vowels created a near one-to-one correspondence of speech sounds to each letter in the alphabet. 
These changes initiated a shift in the writing direction to a rightward one. The importance of the structure of the vocalic alphabet is that it is based on a division of labor between vocalic and consonantal sounds. Essentially, the consonantal sounds indicate the lexical value of words while the vocalic sound apparently modulates grammatical relationships. This inclusion of systematic vocalic sounds indicates that not only the lexical values, but the grammatical values are both represented in the scripts. As a result, unlike with pictographic script, there was no need for readers to supply an oral context (as there still is in Arabic and Hebrew) in order to decipher meaning.

Further, as de Kerckhove (1986) explains that, "the principle of combining letters to form syllables and of combining syllables to form words, enables the reader/writer to perceive and use each level as a separate unit”, (p. 290) suggesting the invention of the Greek vocalic alphabet began the modern era of grammar. He concludes, "Indeed, I am considering the possibility that the adoption of the alphabet by Western culture has had a reordering effect on the brain and the whole nervous system of literate people, including their sensory modes" (p. 291). On this basis, both de Kerckhove and Skoyles suggest that prior to the vocalic alphabet there was a $\mathrm{RH}$ reading orientation, again, suggesting that these changes affected brain laterality by precipitating a shift in reading from an ancient oral RH laterality to a modern literate LH laterality.

\section{Right Hemisphere Reading}

It is important to outline in some detail the claim of ancient $\mathrm{RH}$ reading as it will serve as a kind of bridge to the current NFS hypothesis. Both de Kerckhove (1986) and Skoyles (1988) observe that prior to the invention of the Greek vocalic alphabet, with pictographic scripts all reading and writing was either vertical (up/down) or as it came to be prevalent, horizontal (from right-to-left), concluding that the eye movements during right-to-left reading would access $\mathrm{RH}$ processes. After the invention of the vocalic alphabet all users of this alphabet eventually wrote from left-to-right, implying LH processes. Ruling out cultural causation for this shift of script and reading direction, de Kerckhove (1986) notes that

„one indication that this shift was not simply serendipitous or culturally induced is the fact that among all Semitic (that is, consonantal scripts and their derivatives numbering about 50) there is not a single one which at any time has been written consistently in any other direction than to the left. Conversely, there is hardly a single vocalic script, among several hundreds, which has not been either written rightwards outright, or soon been reverted to the rightward direction within a hundred years after its initial appearance" (p. 280, italics added). 
Skoyles (1988) makes a most interesting set of observations regarding this reading and writing shift that can be applied to the NFS hypothesis of this paper.

Skoyles observations involve what is called mirror reversals. Most right- handed people have some degree of writing ability with their left hand (involving RH). However, shifting to the left hand often tends to produce mirtor reversals: that is, they often produce leftward written letters (see, Schott. 1980). Studies have shown (Bradshaw, Bradley and Patterson, 1976; Harcum \& Finkel, 1963) that though the LH recognizes letters best when they are in their normal (relative) orientation, the RH recognizes mirror forms of letters better. This phenomenon seems to involve the corpus callosum, the major connecting link between the two hemispheres. One view is that the corpus callosum tends to encode the reverse of LH-learned images (see Bradshaw, Bradley, and Patterson, 1976; Corballis, 1974; Noble, 1966; Orton, 1928).

Skoyles points out that the implication of these fmdings is that literacy generated indirectly via the corpus callosum tends to be the mirror reversal of literacy generated in the opposite hemisphere. Apparently, this mirror-reversed literacy is always present but is inhibited under normal conditions. This is indicated by injuries to the LH where individuals can develop the ability to read leftward, while losing the ability to reading rightward (Heilman, Howell, Valenstein and Rothi, 1980). Continuing with the RH reading implications of mirror reversals, Skoyles (1988) explains that, when literacy shifted to the LH, there was likely a transition period in which some readers remained RH literate and others exhibiting the new LH literacy. On the other hand, it is possible there was a transition period where both the LH and RH possessed reading skills, with the LH gradually acquiring more dominance. Bilateral representation would likely have been necessary as a compromise between the LH favoring rightward script and the reverse for the RH. This indeed appears to be what occurred. In the sixth century B.C. Greek was written in boustrophedon format where the first line of a document was written rightward, the second line written leftward, the third line written rightward again, and so forth.

The boustrophedon Style combines the advantages of leftward writing (for the RH ) with rightward writing (for the LH). Skoyles, thus hypothesizes that in reading boustrophedon, the LH read rightward lines and the RH the leftward lines. Alternatively, ancient readers may have possessed a primary reading hemisphere that processed all information received, and a secondary hemisphere that processed only initial perceptual stages prior to communicating its information across the corpus callosum to the main hemisphere. The implications of the latter case would be that, given the LH served as the primary reading hemisphere, a rightward line of boustrophedon would be read normally, whereas for leftward lines, the RH would only read letters partially before transmitting this information across the corpus callosum to the LH to be completed. 
Skoyles (1988) intriguingly observes that hemispheric mirror reversal phenomenon likely explains the reversal in letter orientation that accompanied the change in leftward to rightward direction. When the Greeks adapted the Phoenician alphabet the letter written as "e" became reversed and written as "e". As de Kerckhove (1986) concludes, when the brain has been conditioned to a fully phonetic alphabetic code, it may develop according to the biases characteristic of the special abilities of the LH, which would not be as pronounced in non literate conditions (see below).

There are fiurther fmdings to support the claim that RH reading influences lateralization, de Kerckhove (1986), Ornstein (1997), and Skoyles (1988) all cite the literature showing that in the early stages of children learning to read Hebrew it is their $\mathrm{RH}$ that is more dominant, not their LH. It seems that only after the age of 7 years does their LH becomes dominant (See, Silverberg, Gordon, Pollack, and Dentin 1980).

In addition, there is a considerable body of research showing that, for example, a pictographic script like the Japanese Kanji is represented differently than the Japanese Kana script which is phonetic based, with ideographic Kanji characters being recognized better by the RH than the LH. (see Hatta 1977, 1981; Hatta, Honjoh, and Mito 1983). In addition, it seems that Kanji, the nonphonetic script, leads to different affects after LH injuries than does the phonetic Kana which mainly marks syntactical order and thus may not exhibit the same reading and writing impairments as corresponding Western LH patients. Similar fmding have been noticed for the pictographic Chinese language (Sasanuma, 1975). Finally, Skoyles (1988) notes that blood flow maps during reading show the homologous areas in the RH consume extra energy (indicating activity) like their linguistic counterparts in the LH (See, Larsen, Skinho, \& Lassen, 1979).

Finally, if as Havelock (1963) points out, "The pre Homeric epoch - the Dark Age yields for the historian what might be called a controlled experiment in absolute non literacy" (p. 117), then existing illiterate and non literate populations might serve as models and natural experiments in non literacy - albeit less than perfect - as modern literate cultures still exert their literate influence in numerous non literate ways ${ }^{24}$. Indeed, de Kerckhove (1986), and Skoyles (1988) each open this possibility by citing research with such populations for their RH reading hypothesis. Others, too (Goody, 1977; Luria, 1976; Ornstein, 1997) have suggested that these populations may provide useful findings on nonliteracy affects on cognitive development.

${ }^{24}$ For example, Sirat (1988) observe, "In our society children are influenced by the writing direction of the culture they live in a long time before they learn to read and write. To cite only one example: when the same television game is produced in the US and Israel, the figures enter from the right in the US, from the left in Israel" (p. 175). 
In this regard, Castrocaldas, Petersson, Reis, Stoneelander and Ingvar (1998), conducted research comparing literate with non literate subjects using positron emission tomography (PET) mapping. They compared word and pseudo word repetition in the literate and illiterate subjects. In addition to confirming the typical finding that phonological sounds are processed in the LH, they found that with repeating real words, the two groups performed similarly with similar areas of the brain being activated. In contrast, however, the non-literate subjects had more difficulty repeating pseudo words correctly but more importantly, different neural structures were activated than in literates. The authors conclude that their results are consistent with the hypothesis that learning the written form of language (orthography) influences the functioning of oral language, indicating that learning to read and write during childhood influences the functional organization of the adult brain. Tzavaras, Phocas, Kaprinis and Karavatos (1993), Tzavaras, Kaprinis and Gatzoyas (1981), also conducted study using dichotic listening procedures comparing literate and illiterate and non literate (Greek) subjects for both digits and words. They found that literate people use their right ear more (therefore their LH) for listening to words. The non-literate and functionally illiterate subjects used their left ear more, thereby showing right hemispheric activation more than literate subjects.

\section{The NFS Hypothesis}

At this juncture, it is important to note that the NFS being hypothesized occurred in post vocalic-alphabet Greece was a relative and functional, not an absolute one. There is evidence of hemispheric shifts that can serve as illustrations of more permanent NFS. It is well known, for example, that in the ordinary course of cognitive functioning, hemispheric shifts are frequent in accommodating to different tasks. Ornstein (1997) found that, "ordinary people, doing ordinary activities, turned on and off the two sides of their brain appropriately" (p. 72) ${ }^{25}$. He further found that the RH showed more alpha wave (idling) activity than the $\mathrm{LH}$ while writing a letter, and the LH showed more beta wave activity, whereas arranging blocks showed more $\mathrm{LH}$ alpha than the $\mathrm{RH}$, while the $\mathrm{RH}$ showed more beta waves. Thus people shift from one hemisphere to another depending on the task. Kosslyn and Koenig (1995) similarly note, "each hemisphere may

${ }^{25}$ It is interesting from an evolutionary perspective that some species of dolphins have evolved an extreme mechanism of hemispheric shifting and disconnection (Herman, 1980; Mukhametov, 1988). It seems that dolphins sleep by shutting down only one side of their cerebral cortex at a time, then shifting to the other, presumably so that they can keep moving and surface for air (see next endnote). 
inhibit high-level processing in the other hemisphere. Indeed, at higher levels of processing, attention seems to have its effects at least in part by inhibiting competing processing" (p. 423), thus exhibiting a NFS.

Other more striking evidence indicates that less momentary shifts in laterality for language processing may occur as a learned adaptation. Deacon (1997) cites data from schools that train verbal language translators, such as those hired by the United Nations to listen and provide simultaneously translations. He suggests that under these special linguistic demands both hemispheres can become language hemispheres. It seems the problem for simultaneous translators is to keep the two languages from competing and interfering with each other. Consequently, most translators apparently develop an ear preference for listening to the source language and another for the translation. Studies pre and post training demonstrate that most students begin with the typical right ear (i.e., LH) preference for both languages, but by the end of training develop an opposite ear advantage for each language. Self selection, notwithstanding, Deacon concludes that this situation likely demonstrates the general principle that when sensorimotor or cognitive operations tend to compete for the same neural substrate resources, selection pressures to segregate the competing operations into the opposite hemisphere are developed.

Similarly, though research based on dichotic listening procedures with musical tones have clearly shown an RH advantage, when trained musicians hear musical sounds the LH becomes increasingly involved. (Ornstein, R. (1997). This is perhaps a musical parallel to hemispheric differences that occur with literacy. Further supporting evidence for a NFS can be found in a classic article by Galin (1974). Though somewhat more controversial than the above research, Galin suggests that similar to split-brain patients where the connecting corpus callosum is severed, a hemisphere can be functionally dissociated or relatively disconnected (or inhibited) in the intact brain. According to Galin, although each hemisphere is exposed to the same sensory input, it effectively receives a different input because each emphasizes a different aspect of a stimulus "message". For example, the LH may attend to verbal cues, and the RH to nonverbal cues in a message. Under these conditions, the two hemispheres may respond with opposite courses of action, with the LH attending and the $\mathrm{RH}$ avoiding different aspects of a message. While the $\mathrm{LH}$ controls responses most of the time, if the $\mathrm{LH}$ is not able to override the $\mathrm{RH}$, it may functionally "disconnect" the transfer of the conflicting information by dampening down transmission of impulses across the corpus callosum. Galin believes that during such moments of functional disconnection, the LH solely governs consciousness ${ }^{26}$. While Galin specifically applies this to

${ }^{26}$ Galin's functional disconnection syndrome has been invoked to explain alexithymia, a relatively extreme condition of being unable to access feeling and/or to explain them in words. In discussing 
the $\mathrm{LH}$ disconnecting the $\mathrm{RH}$, given all of the foregoing, it seems reasonable to infer that the opposite dampening could also occur, i.e., that the RH could dampen the $\mathrm{LH}$, leaving the RH relatively dominant. NFSs of short duration, then, do occur as the consequence of (a) environment, (b) learning, (c) task competition, and (d) inhibition processes. In addition, there are developmental neurological fmdings congruent with a NFS.

In reviewing the literature on hemispheric development, Kosslyn and Koenig (1995) point out that research suggests the RH is more mature at birth than the $\mathrm{LH}$ (see De Schonen and Mathivet, 1989; Geschwind and Behan, 1984; Geschwind and Galaburda, 1985). Equally important is the connecting trunk, the corpus callosum which is not mature at birth (Witelson and Kigar, 1988) with only about two-thirds of its fibers myelinated. Indeed, it may not be mature until around age 12. The implications of these findings are important for the NFS hypothesis. First, the LH and the corpus callosum not being mature at birth could give the RH an initial developmental advantage - at least for certain kinds of tasks. Interestingly, Keil (1986) found that children seem to make a developmental shift at around 8 years when most metaphors relating two domains are then understood. What is more, it seems that in the early stages of children learning to read Hebrew (right-to-left reading) it is their $\mathrm{RH}$ that is more dominant not their LH which, only after the age of 7 becomes dominant (see, de Kerckhove (1986), Ornstein (1997), Skoyles (1988), Silverberg, Gordon, Pollack, and Dentin 1980). Interesting, too, in this regard is that children reversing letters like $b$ and $d$ tend to cease this reversal around 8 years of age or so, just when the corpus callosum is becoming mature (see reversal issue below) ${ }^{27}$.

In further discussing variables determining laterality, Kosslyn and Koenig (1995) suggest a "snowball effect" whereby whichever hemisphere is first "initialized" could give that hemisphere an advantage which then compounds on itself. Adapting Kosslyn and Koenig's snowball effect to the NFS hypothesis, it is possible that since the RH is more mature at birth, and the corpus callosum is immature, until perhaps around age 12, the RH may under non literate conditions be initially favored over the $\mathrm{LH}$, which then may lead to a continued RH dominance, or at least exerting more influence than what is currently considered

Galin's functional disconnection syndrome and its RH association, Kissin, (1986) also notes the paucity of dreams, and the operational thinking in commissurotomized, also RH associated phenomena . Kissin also cites neurological fmdings which lead him to believe that differential hemispheric channeling is most likely to occur through screening at the subcortical level.

${ }^{27}$ The reversal across the corpus callosum seems to be a memory problem not a perceptual one. For example, with young children and dyslexics, the common reversal occurrence of mistaking $b$ for $d$ and $p$ for $q$ does not appear to be a perceptual problem. Interesting, too, is that children seem to make a developmental shift around age 8 , an age when most metaphors relating two domains are then understood. 
normal for certain tasks or functions - in this case language. This is consistent with the above hemispheric testing on non-literates. With regard to this relative NFS and its functioning, unlike much of the evidence cited here which were gathered from clinical syndromes, the hypothesized RH dominant functioning would be occurring in intact brains. This has numerous and important implications for the NFS hypothesis regarding the primacy of figurative language under nonliterate conditions.

First, a RH dominance, with its relative lack of linguistic ability (as currently conceptualized) would still be augmented - as indeed it is normally - by the linguistic ability of the LH, the LH language would be more heavily influenced by RH associated processes than it is now thought to be. Hence, normal language would be much more metaphorical. Though it is hypothesized that the dominance of the $\mathrm{RH}$ is made possible by (a) the relative earlier maturity of the $\mathrm{RH}$, which

(b) under preliterate condition would be "initialized" earlier than the LH, leading

(c) to a subsequent "snowballing effect", of its early dominance and/or (d) a functional dampening down of the corpus callosum, an everyday $\mathrm{RH}$ dominated language production would still be phonetically and predominantly generated by the LH, but the RH would exert much more influence in terms of the emotional and cognitive processes subserving semantic selection and meaning. In the case of corpus callosum activity being dampened down, thereby reducing information across the corpus callosum, other routes through the collicular and anterior commissures could cue or leak to the LH, as indeed a considerable amount of research with various neurological disconnection syndromes, has consistently demonstrated.

In various disorders like the neglect syndrome, blindsight, and cortical blindness (see Wieskarantz, 1986) where the consequence of damage to certain neurological tissue involved in vision patients do not consciously "see" objects when looking at them. However, when asked to guess or when forced to select from an array of objects their "guesses" achieve statistically better than chance levels of choosing the correct objects. Similar findings have been found with split brain subjects (e.g., LeDoux, 1996; Springer and Deutsch, 1981; . In other words, input was neurologically registered on lower subcortical levels which was then "leaked" to some level of preconscious awareness as indicated by the correct guesses. Given this, it seems reasonable to hypothesize that a metaphorically skilled and dominant RH could shape the generation of speech out of the $\mathrm{LH}$ rendering it at least much more figurative than in contemporary literacy-based $\mathrm{LH}$ dominant language.

If this NFS hypothesis is tentatively accepted, then the so-called "fixed" and "traditional" metaphors of Homer may not, as Parry (1971 b, 1971 c) suggests, be clichelike figures of speech taken from an otherwise literal everyday vernacular of the times, nor are they like what are now called "dead" or "literal" metaphors, but instead reflect an ancient oral tradition language that was largely 
metaphorical or "poetic", which through usage became literal. As the consequence of the widespread adoption of the vocalic alphabet and the subsequent NFS from RH to LH dominance later interpreters of these figurative phrases considered them deviations from a generally spoken "literal" language. There remains one fmal piece of the puzzle to complete this initial formulation of the NFS hypothesis, and that would explain how the everyday language in ancient Greece could be heavily "poetic" or figurative. The final piece is the role of emotion or affect in metaphor generation.

Unlike the modem literate LH generation of lexical metaphor, the ancient oral RH metaphoric utterances were likely generated from an affective or psychoemotional base. Just as poets often describe the origin of their verse as generated by feelings, so too it is likely that ancient metaphor was generated out of a feeling-based matrix (see Haskell, $1989,1982,1978)^{28}$. This would be consistent with a RH associated influence. From research on split brain subjects, for example, it is well known that strong (albeit typically negative) feelings are associated with the RH (e.g., Le Doux, 1996; Ornstein, 1977; Deutsch and Deutsch, 1981). Briefly, this psychoemotional process of ancient metaphor generation can be seen as what is called a holophrastic transformation, for example, when an insult is emotionally experienced and linguistically expressed as feeling like a "slap in the face" or "felt like someone hit me right in the stomach". The affective basis of metaphor is also consistent with what is known as synesthesia, the transposition or transfer of sensory experience from one sense modality to another, as in perceiving a high note of music to be "bright", "sharp", or "tinny". The synesthetic process is what Marks and Bornstein (1987) refer to as cross-modal transfer. True synesthesia is characterized by actually "seeing" sounds, or "hearing" colors. True synesthetes appear to be neurologically cross "wired", thus producing neurological or "hard wired metaphors". For Marks, synesthesia is the basis for what are sensory metaphors and has its origin in cross-modal sensory processing.

Accordingly, unlike today, an ancient language could have been largely figurative or metaphorical ${ }^{29}$, though not in the "poetic" sense of Jaynes, Rousseau,

28 Affective schemata often seem to activate, merge with and shape conscious literal linguistic productions. I have found (Haskell, 1991,1989,1982, 1978), for example, that in a conversation where there is an affective concern about being tape recorded (even when aware of the recording) people will select into the conversation stories about the CIA or FBI secreting wiretapping people. In other words, the stories about the CIA and FBI are "metaphorical" expressions of their affective concerns. Repeatedly, these people have no conscious recognition of why these stories were selected into the conversation. Somehow the non conscious affective concerns cue the linguistic selections. While they are otherwise literal stories, they call into question the very definition of what constitutes literal v. metaphoric (see endnote \# 1).

29 In our high tech culture we tend to not appreciate the influence of culture on mental and emotional states. As in many preliterate cultures, it is fairly clear that the ancient Greeks exhibited 
and $\mathrm{Vico}^{30}$. The situation would have been the flip side, or reverse of the modem literate tradition with figurative language predominating and literal language occurring at a much lower frequency ${ }^{31}$. On this view, the basis of modem poetry can be seen as the vestigial remains of a RH-associated language functioning. From the NFS perspective, then, Parry's (1971b, 1971c) view of Homer's metaphors being "fixed" cliche-like phrasing from an otherwise predominantly literal language would not be correct, being the consequence of the superimposing of a literate $\mathrm{LH}$ orientation on to a preliterate $\mathrm{RH}$ language community. Further, this RH associated affective or emotive-base view of "live" metaphoric language explains and provides the missing historical foundation for Lakoff and Johnson's view that all literal language is composed of dead and fixed metaphors that were once "live" 32 .

\section{Neurological Findings Consistent with RH Dominance}

Research from a broad spectrum of studies (Chernigovskaya, 1994; Kosslyn, and Koenig, 1995) supports the general consensus that metaphoric understanding

"magical thinking" with their beliefs in multiple Gods and spirits who were thought to influence their lives and actions. It is not unreasonable to assume that this "magical" cultural state could provide an affective base for generating a "poetic" language. From a social psychological and anthropological perspective, for example, there is ample evidence for mass hysterias and hallucinations. In addition it is known that during the early 1700s people often went into convulsions when hypnotic trance was induced (Owen, 1971). This never occurs today. The explanation being the culture of the times was one of belief in demons, spirits, exorcism, and the associations of hypnotic trance with epilepsy. Similarly in the early days of working with what are called multiple personalities using hypnosis, they too, often went into convulsions when switching personalities. This, too, never happens today. In more modern times, in the psychopathology literature of the 1940s and 50s the Freudian symptomology called conversion reactions where patients would exhibit functional blindness or paralysis - that is, these conditions were psychologically induced, with no organic cause - was relatively widespread. Today conversion reactions or hysterical symptoms, as they were sometimes called, are virtually nonexistent. As a culture we have become too knowledgeable about psychological phenomena. Symptomology changes with the cultural belief system (Ellenberger, 1970).

${ }^{30}$ It is arguable whether Jaynes, Rousseau, and Vico meant the term "poetic" in its modern literacybased instantiation. My own take is that they did not.

31 Studies reviewed and by Pollio, Smith and Pollio (1990) suggest that even with a restricted definition of lexical metaphor their frequency in standard speech is in the vicinity 1.5 novel and 4.3 cliche'd figures per 100 spoken words.

32 Unlike most of their cognitive science colleagues, Lakoff and Johnson (1989, see pp. 380- - 415) understand the affective basis of metaphoric language, in particular that emotions can be cognitive/conceptual. While they apply this emotive base in showing how current examples of dead and fixed metaphors were once "live", e.g., the role of anger in creating the metaphorical 
resides largely in the right hemisphere (RH): research from PET scans (Bottini, 1994), brain intact subjects (Anaki, Faust, and Kravetz. 1998), from epileptics (McIntyre, Pritchard and Lombroso 1974); and from other studies involving stroke and other brain damage subjects (Winner, and Gardner 1977). It is now also generally agreed that metaphors are processed and understood just as quickly as literal language as the review by Glucksberg (1998) indicates. This implies that metaphoric language is not linguistically deviant or derived from literal language.

Given (a) that metaphoric capacity is largely associated with RH functioning, (b) that the RH has some linguistic and reading ability, (c) that the Iliad and to a lesser extent the Odyssey are not poetry in the modem sense but the consequence of linguistic and mnemonic mechanics imposed by an oral mode of production, (d) that the thesis that the ancient Greek oral tradition was characterized by RH reading, (e) that current research on illiterate and non literate populations suggests that literacy influences lateralization, and (f) that non literate populations seem more governed by $\mathrm{RH}$ processes, is there neurological evidence to support a RH functioning in ancient oral Greece and thus further support the NFS hypothesis of this paper?

The linguistic and cognitive analyses of the oral-based Iliad and the Odyssey by Havelock, (1963), Jaynes (1976), Parry (1971a), and Snell (1953) as well as other research on orality (Goody, 1977, Luria, 1976, Ong, 1982), suggest a number of characteristics of these oral narratives that stand out ${ }^{33}$ : These characteristics seem to be consistent with what is known to be associated with both illiterate and non literate cognitive processes and with RH associated functions.

(1) Story or narrative generation. In an oral culture the mode of transmitting tradition and other information is, of course, the story or oral narrative. First, it seems reasonably clear that the story or narrative mode is primarily associated with RH functioning. For example, based on their research, Kosslyn and Koenig, (1995) conclude that "there are subsystems that abstract elements of the meanings of words and "generate a story" based on these elements" (p.245). They further suggest that, "It seems likely, that such subsystems are distinct from those used in semantic and syntactic processing, given that these reasoning processes apparently are more effective in the right hemisphere than the left (for most right-handed people), whereas the processes that compute the literal meanings of words and sentences are more effective in the left hemisphere"(p. 245, italics added). Similarly, Ornstein (1997), too, fmds that the RH is activated when folk stories are read but not when technical (i.e., literal?) material is read (the FH,

phrase "hot under the collar", it is still not clear how they apply this to the historical origins of lexical metaphor. They do not seem to be taking the position that language was once entirely poetic in the sense of this NFS hypothesis.

${ }^{33}$ I certainly am not competent here. I leave this to others to other to flesh this out. 
however, was activated with both kinds of materials). The apparent reason is that technical material is generally imageless, while stories generate imagery. Similarly, on the basis of her own research and that of others, Chiarello (1991) also concludes that RH damaged patients (leaving the LH) find it difficult to order individual sentences into a coherent story $^{34}$.

(2) Causal inferences. A characteristic of oral traditions and stories is that they seem not to employ causal inferences. Since the RH is strongly associated with metaphoric relations, it might be expected that it would be good at making inferences (see, Beeman, 1991). From studies on commisurotomy patients, Gazzaniga (1992) reports, however, that the RH is poor at making simple - and causal - inferences. For example, when shown a picture of a match and wood pile presented to the RH, the RH cannot abstract the causal relation and choose a burning woodpile. Similarly, when the words "pin" and "finger" are presented to the RH, while subjects cannot select the correct answer, "bleed", the right hemisphere could always find a close lexical associate of all of the words used when tested separately, it could not make the inference that "pin" and "finger" should result in the answer "bleed."

(3) Rigidity and formulaic structure. A characteristic of oral traditions and stories is that they are concrete and rigid in their order and presentation. (Chernigovskaya, 1994). Rigidity appears to be a characteristic associated with RH functioning Zaidel (1994) suggests that $\mathrm{RH}$ rigidity is probably a requirement for a cognitive system that specializes in spatial perception and recognition ${ }^{35}$.

34 Hilgard (1977 ) investigated story generation under hypnosis. One subject who normally told extensive, creative and coherent stories, under hypnosis "revealed that there was a part of him doing the planning, more like a stage director providing the promptings for the hypnotized part, the actor. The hidden part knew, for example, that the cavern was to have a beautiful room and that there would be a garden beyond. The hypnotized part did not know their qualities until seeing them. As he put it, "The two parts worked together to form a story". The hidden part also planned antd monitored the length of the story (p.195). Hilgard suggests that his fmdings open up the

possibility of parallel processing in other mental processes. He quotes English poet, A. E. Housman's description of his writing poetry: "...there would flow into my mind, with sudden and unaccountable emotion, sometimes a line or two of verse, sometimes a whole stanza at once, accompanied, not preceded, by a vague notion of the poem which they were destined to become a part of'. Housman was describing the unconscious work being done before conscious recognition. Novelists often describe their characters as "taking over" and the story plot automatically unfolding without conscious planning. The similarities here to processes in the disconnected $\mathrm{RH}$ in split brain subjects seems clear.

35 In terms of cognitive rigidity, Ong (1982) relates the following common experience with a young relative of his, a child young enough to still exhibit an oral mind set, though as he notes, we influenced by the literacy around her. In telling her the story of'The Three Little Pigs': 'He huffed and he puffed, and he huffed and he puffed, and he huffed and he puffed', the child "bridled

at the formula I used. She knew the story, and my formula was not what she expected. 'He huffed 
(4) Fitting of unfamiliar situations into the familiar, the conventional, and the traditional. Fundamentally related to metaphorical perception and reasoning, of course, is the concept of similarity. The research on RH matching of concrete similarity relations, however, appears contradictory. On the one hand, Zaidel (1994) suggests that the RH specializes more than does the left in processing standard or stereotypical concepts (thus implying similarity matching, see below), and Cronin-Golumb (1995) suggests that the $\mathrm{RH}$ is specialized for conventional meaning, where as the LH is specialized to process deviations from standard meaning. On the other hand, and counterintuitively, Gazzaniga (1992) fmds that split-brain subjects (without RH language) have little or no ability for responding to patterned stimuli; their RH apparently does not easily make simple same/ /different or matching judgments. Conceptually, this leads to the problem of how judgments of what is "standard" stereotypical and"conventional" are made in the absence of similarity/difference matchings, since making judgments about whether something is standard or conventional requires that it be matched or compared to something else.

Such contradictory fmdings must be the result of either different research methodologies, the type of subjects used, e.g., brain injured vs. brain intact subject, and/or the consequence of using different materials and task requirements. For example, Chiarello and Church (1986) studied similarity judgments in both LH and RH damaged patients using rhyme, visual similarity, and meaning tasks. They found that while RH patients demonstrated some impairment on the semantic task, they were less impaired on all tasks than were the LH patients. Further, if, inference is taken to mean non causal and those not requiring a reinterpretation of a $\mathrm{RH}$ damaged subjects original literal interpretation (Chiarello, 1991), but rather inference based on contextual and other information, the answer is likely yes. Citing her own and other research, she suggest that RH patients do not have "inferences deficits per se. Such patients are able to make bridging inferences, as long as these do not require reinterpretation. RH patients could infer a character's implicit attitude (positive or negative) when it was not directly stated. The same patients could not, however, correctly interpret a character's attitude when a final statement, in its literal form, contradicted expectations built up from earlier information. In such cases, the final statement is best interpreted sarcastically. RH patients apparently could not draw this inference because they could not revise their original literal interpretation" (p. 268). And de Kerckhove

and he puffed, and he puffed and he huffed, and he huffed and he puffed', she pouted. I reworded the narrative, complying to audience demand for what had been said before, as other oral narrators have often done" (p. 67). Both Chernigovskaya (1994) and Skoyles (1988) - and correctly, I think - note the parallels between the cognitive effects of non literacy and the cognitive characteristics of young children. 
(1986), also finds a form of inference in the literature on RH reading based on context (albeit a narrow one).

In any event, these contradictions and inconsistencies are not necessarily a serious problem for the NFS hypothesis if, as Metcalfe, Funnel, and Gazzaniga (1995) maintain, the critical aspect for the RH and similarity appears to be items that are distinguishable from but which are "in the same class" as other items presented (p. 162), thus implying similarity judgments: How else are events typically assigned to a "class" 36 .

(5) Memory storage requirements. Being historical storage and instructional systems for preserving and transmitting factual social history, the oral based Iliad and the Odyssey would require its reciters to be able to store and retrieve from memory large amounts of data. Relative to the LH, the RH seems a better candidate for storing large amounts of information. Most researchers agree that metaphorical polysemy would require the storage of a large stock of separate words. Both Chernigovskaya, 1994 and Chiarello (1991) suggest that it is the RH that stores the many multiple meanings of words, which the LH narrows to the correct one for the given situation.

(6) Factual memory requirements. As historical storage and instructional instruments for preserving and transmitting social history, the reciters of the ancient Greek narratives would require a capacity for veridical (factual) memory. Relative to the $\mathrm{LH}$, the RH seems a better candidate for retaining veridical information and making veridical matches. Reviewing the literature, Metcalfe, Funnel, and Gazzaniga, (1995) and Marsolek, Kosslyn, and Squire 1992) suggest research provides evidence that the RH stores more exact memory traces than does the left hemisphere. The apparent reason for this is that human cognition includes generalizations, conjectures, inferences, and fantasies, all, presumably being enacted primarily with the LH. Otherwise, such a complex cognitive organism, they point out, would be vulnerable to confusing constructed internal events for real memories of external events were it not for a system that (a) tends not to enact these complex operations, (b) does not store the results, and hence (c) is not confused by them. Metcalfe, Funnel, and Gazzaniga (1995) suggest that the more veridical RH memory system may have a crucial adaptive function - "'allowing the interpretations, interpolations, and inferences of the left hemisphere while still maintaining an accurate record of the past" (p. 163) in the RH.

(7) Concrete mode of thinking. One of the clear characteristics that the ancient Greek oral texts reflect is their extremely concrete mode of thought. There seem

${ }^{36}$ Second - and most importantly - and at some risk of circular reasoning, since the NFS is hypothesized to be a relative, not an absolute one, there is no necessary contradiction. In the intact brain there is no total disconnection of hemispheres, thus allowing cross talk either across the corpus callousm and/or cuing trom other commissures, or from subcortical areas (see text). 
little or no abstract sense of categorization, formal principles of explanation, definitions, or logical syllogistic-type reasoning. Everything is described in concrete, immediate and practical/action terms. The characteristic of concreteness is also most clearly reflected in the contemporary research on illiterate and nonliterate populations. Beginning perhaps with the work of the Russian psychologist A. R. Luria (1976). Luria found that populations lacking in literacy engaged in a most extreme concrete thinking. For example, when shown a geometric figure like a circle subjects would call it a plate, sieve, bucket, watch, or moon; a square would be labeled a mirror, door, house, apricot drying-board, all things in their immediate practical experience.

Shown the objects hatnmer, saw, log, and hatchet, illiterate subjects consistently thought of them not in abstract categorical terms as three tools, with the log not belonging to the group, but thought of them in terms of practical situations. They described them as all alike: The saw will saw the log and the hatchet will chop it into pieces, saying that if one of the objects had be omitted that they would throw out the hatchet since it doesn't do as good a job as a saw. Similarly, in terms of logical inference and syllogistic reasoning, when they were informed that in the Far North, where there is snow, all the bears are white, and then asked what color are the bears in Novaya Zembla, a town in the Far North where there is always snow, typically responded, “I don't know. I've seen a black bear. I've never seen any others (pp. 108-9). Requests for definitions, of even the most concrete objects, for example of a tree, was responded to with "Why should I? Everyone knows what a tree is, they don't need me telling them" (p. 86). This concrete mode of reasoning seems to be common among illiterate and non-literate populations.

The question now is, is this kind of reasoning RH associated? In partial answer, recall Gazzaniga's (1992) above fmdings with split brain subjects that the RH is poor at making simple causal inferences, such that when shown a picture of a match and wood pile are presented to the $\mathrm{RH}$, it could not abstract the causal relation and choose a burning woodpile.

(8) Word order and selection. The linguistic structure of the Iliad is characterized by word choice not being selected as much by syntactical rules (or by meaning) as by the form and position of the word so as to fit the hexameter line and other formulaic phrasings. Again, assuming the Iliad is not poetry in the modern literate sense, the peculiar word selection and order would not be the consequence of constructing poetic verse, but a characteristic of RH functioning, since it is well-known that, in contrast to the LH, the RH has little to no sense of syntax. Research by Chernigovskaya (1994) found that with illiterate brain-intact Russian subjects that word position was the predominant factor in word selection. Chernigovskaya believes this to be a characteristic of RH language. While she notes that this characteristic may be due to the Russian language which, unlike 
English is highly inflected, this characteristic of using initial position instead of syntax for word selection is also a characterisfic of early language construction in young children.

(9) Moral sense. The Iliad appears to have no concept or understanding of morality in the abstract and modem sense. Both Havelock (1963) and Jaynes, (1976), lay this to a different consciousness (though in differing senses of the word consciousness) than exists today. Havelock explains it in terms of an oral culture and Jaynes to his Bicameral Mind thesis. Either way, it seems the characters in the Iliad are incapable of an abstract sense of morality. The findings on RH functioning and on the effects of illiteracy are consistent with this observation. RH damaged patients have difficulty in extracting the moral of the story or the abstract motivation of characters in a narrative despite an adequate "factual" understanding (Chiarello, 1991; Gardner, Brownell, Wapner, and Michelow, 1983; Wapner, Hamby, and Gardner, H. (1981).

(10) Negative affect. The Iliad is mostly characterized by high negative emotionality. It is well known in the lateralization literature that the RH tends to be associated with more emotion and negativity than the LH (see, Le Doux, 1996; Ornstein, 1997; Springer and Deutsch, 1981). See endnote $27^{37}$.

Finally, (11) Singing-like cadence and rhythm. It is now fairly well accepted by classicists that the Iliad was recited by minstrels who sang the verses, like minstrels in oral cultures do today (see Parry, 1971 a; Havelock, 1963) ${ }^{38}$. It is also well known that musical sounds are largely associated with the RH (e.g., Zaidel, 1994), and can function as a mnemonic aide. However, just as it is unlikely, as Vico, Rousseau, and Jaynes suggest, that ancient Greeks constantly spoke poetically, it is unlikely that they went around singing all day. From an orality respective, it is, however, likely that they engaged in sin ing-like cadences

henever they had to recall considerable amount of material from memory ${ }^{39}$.

Given the array of historical, cognitive, and neurological fmdings applied to this inquiry into the origin of lexical metaphor it seems at least prima faci that research into the cognitive bases of metaphor, along with what constitutes what

Ornstein (1997) explains these findings as the consequence of the RH managing the facial and large muscle movements of the arms and legs, and that such negative emotions typically require large actions. In the weaker form of the hypotheses Vico, and Jaynes suggest all language was originally song-like. For a clear exposition of Vico's view see Trabant (1991). While it is perhaps doubtful if language production was ever completely musical (except for minstrels) music and the singing of lyrics, of course, are powerful mnemonic devices. Few people have not had the experience of being able to recall the lyrics of a song without first begirming to sing it.

Recall the singsong way children used to learn and recite the alphabet and the way children learn the musical advertisements on T.V. Perhaps, too, the cadence seen in the Catholic High Mass in Latin also reflects these early origins. 
is called metaphor, would benefit from expanding the kinds of data used here in future investigations.

\section{Conclusion}

Given the sketchy nature of both the content and data used here, the NFS hypothesis will undoubtedly engender considerable controversy - indeed as it should. While the hypothesis has considerable explanatory power and is robust, it certainly raises more questions and issues than it answers and solves. If it serves no other purpose, however, than to open new areas of questioning and interdisciplinary research between cognitive science and the humanities regarding the origin of metaphoric cognition, it will have accomplished a much needed function. At the very least, it should serve (a) as a heuristic for a shift in focus in research on figurative language, (b) to shift research from a dry (linguistic and computational) to wet (neurological) brain approach, (c) to incorporate research on cognitive development under, (c) orality and illiteracy conditions. If the NFS hypothesis turns out to have more than a heuristic function serving as a spur to interdisciplinary collaboration then based on the data presented intriguing future developments for metaphor and language research may be forthcoming from both the cognitive and humanities literatures.

\section{References}

Anaki, D, Faust, M and Kravetz. S. (1998). Cerebral hemispheric asymmetries in processing lexical metaphors. Neuropsychologia, $36,691-700$.

Anderson, C. C. (1964). The psychology metaphor. Journal of Genetic Psychology, 19,5 5373.

Baldwin, C. S. (1959). Ancient rhetoric and poetic. Gloucester, MA: Peter Smith. Beeman, M. (1991). Semantic processing in the right hemisphere may contribute to drawing inferences from discourse. Brain and Language, 44, 80-120.

Best, C. T. and Avery, R. A. (1999). Left-hemisphere advantage for click consonants is determined by linguistic significance and experience. Psychological Science, 10, 65-70. Black, M. (1962). Models and metaphors. Ithaca, New York: Cornell University Press. Boon, J. (1972). From symbolism to structuralism. New York: Harper Torchbooks. Borowy T. and R. Goebel (1976). Cerebral lateralization of speech: The effects of age, sex, race, and socioeconomic class. Neuropsychologia 14, 363-370.

Bottini, G., Corcoran, R., Sterzi, R., Paulesu, E., et al. (1994). The role of the right hemisphere in the interpretation of figurative aspects of language: A positron emission tomography activation study. Brain, 117 (6) 1241-1253. 
Bradshaw, J., Bradley, D. and Patterson, K. (1976). The pereeption and identification of mirrorreversed patterns. Quarterly Journal ofExperimental Psychology, 28, 221- -246. Bruner, J. (1990). Acts ofmeaning. Cambridge, M.A.: Harvard University Press.

Castrocaldas A. Petersson, K. M., Reis A., Stoneelander S. and Ingvar, M.(1998 ). The illiterate brain - learning to read and write during childhood influences: The functional organization of the adult brain. Brain. 121(Part 6): 1053-1063.

Changeux, J. (1983). L'Homme neuronal. Paris: Fayard.

Chernigovskaya, T.V .(1994). Cerebral lateralization for cognitive and linguistic abilities: neuropsychological and cultural aspects. Studies in Language Origins, 3, 55-76.

Chiarello, C. (1991). Interpretation of word meanings by the cerebral hemispheres: One is not enough. In The psychology of word meanings. (Ed.), P. J. Schwanenflugel. Hillsdale, New Jersey: Lawrence Erlbaum.

Chiarello, C. and Church, K. L. (1986). Lexical judgments after right- or left-hemisphere injury. Neurophychologia, 24, 623-630.

Cooper, L. (I960). The rhetoric of Aristotle. New York: Appleton-Century-Crofts. Corballis, M.C. (1974). The left right problem in psychology. The Canadian Psychologist, $15,16-33$.

Crocker, J. and Sapir, D. (Eds.), (1977). The social use of metaphor: An anthropology of rhetoric. Philadelphia: University of Pennsylvania Press.

Cronin-Golomb, A. (1995). Semantic networks in the divided cerebral hemispheres. Psychological Science, 6, 212-218.

urtiss, S. (1989). The independence and task-specificity of language. In Interaction in human development. (Eds.), M. H. Bornstein, and Bruner, J. Hillsdale, New Jersey: Lawrence Erlbaum.

Danesi, M. (1995). Giambattista Vico and the cognitive science enterprise. (Emory Vico Studies, vol. 4). New York: Peter I,ang Publishing.

Danesi, M. (1993). Vico metaphor and the origin of language. Bloomington, IN. Indiana University Press.

de Kerckhove, D. (1986). Alphabetic literacy and brain processes. Visible Language, 20 (3), 274-293.

Deacon, T. (1997). The symbolic species: The co-evolution of language and the brain. New York: W. W. Norton.

de Schonen, S., and Mathivet, E. (1989). First come, first served: A scenario about the development of hemispheric specialization in face recognition during infancy. European Bulletin of Cognitive Psychology, 7, 3-44.

Dorman, M. F. and Geffner. D. (1974). Hemispheric specialization for speech perception in six year old black and white children from low and middle socioeconomic classes. Cortex 10, 171-176.

Dreistadt, R.(1968). An analysis of the use of analogies and metaphors in science. The Journal of Psychology, 68, 97-116

Edelman, G. M. (1989). The remembered present: A biological theory of consciousness. New York: Basic Books.

Eisenstadt, S. N. (Ed.), (1986). The origins and diversity of axial age civilizations. New York: SUNY Press. 
Ellenberger, H. E, (1970). The discovery of the unconscious: The history and evolution of dynamic psychiatry. New York, Basic Books.

Fernandez, J. (1972). Persuasions and performances: Of the breast in everybody...and the metaphors of everyman. Daedalus, (winter) 39-60.

Galin D., Ornstein R., Herron J. and Johnstone J. (1982). Sex and handedness differences in EEG measures of hemispheric specialization. Brain Language, 16, 19-55

Galin, D. (1974). Implications of psychiatry of left and right cerebral specialization. Archives of General Psychiatry, 31, 572-582.

Gardner, H., Brownell, H. H., Wapner, W. and Michelow, D. (1983). Missing the point: The role of the right hemisphere in the processing of complex linguistic materials. In E. Perecman (Ed.), Cognitive processes in the right hemisphere. New York: Academic Press. Gazzaniga, M. (1992). Nature's Mind. New York: Basic Books.

Gazzaniga, M. (1985). The social brain. New York: Basic Books.

Geschwind, N., and Behan, P. O. (1984). Laterality, hormones, and immunity. In N. Geschwind, and Galaburda , A. M. (Eds.), Cerebral dominance: The biological foundations. Cambridge, MA: Harvard, University Press.

Geschwind, N. and Galaburda, A. M. (1985). Cerebral Lateralization. Archives of Neurology, $42,428^{\wedge} 159$.

Geffner D. S. and Hochberg, I. (1971). Ear laterality performance of children from low and middle socioeconomic levels on a verbal dichotic listening task. Cortex 7, 193-203.

Gibran, K. (1976). The Prophet. New York: Alfred A Knopf.

Glucksberg, S. (1998). Understanding metaphors. Current Directions in Psychological Science, 7 (2), 39-43.

Goody, J. (1977). The domestication of the savage mind. New York: Cambridge University Press.

Harcum, E. R. and Finkel, M. E. (1963). Explanation of Mishkin and Forgay's result as a direction reading conflict. Canadian Journal of Psychology 17, 224-235.

Haskell, R. E. (In press). Unconscious Communication: Communicative Psychoanalysis and Subliteral Cognition. Journal of the American Academy of Psychoanalysis, 27, (3), 47502.

Haskell, R. E. (1999). Between the Lines: Unconscious meaning in everyday conversation. New York: Plenum/Insight Books.

Haskell, R. E. (1993). Vico and Jaynes: Neurocultural and cognitive operations in the origin of consciousness. New Vico Studies, 11. 24-51.

Haskell, R. E. (1991 ). An analogical methodology for the analysis and validation of anomalous cognitive and linguistic operations in small group (fantasy theme) Reports. Small Group Research, an International Journal of Theory, Investigation and Application, 22, 443-474.

Haskell, R. E. (1989). Analogical transforms: A cognitive theory of the origin and development of equivalence transformation, Part I ,11, Metaphor and Symbolic Activity, 4, 247-259, 257-277.

Haskell, R. E. (Ed.), (1987). Cognition and symbolic structures: The Psychology of metaphoric transformation 
Haskell, R. E. (1987a). Structural metaphor, and cognition. In: R. E. Haskell. (Ed.). Cognition and symbolic structures: The Psychology of metaphoric Transformation. Norwood, New Jersey: Ablex Publishing.

Haskell, R. E. (1987b). Giambattista Vico and the discovery of metaphor. In: R. E. Haskell. (Ed.). Cognition and

Haskell, R. E. (1982). The matrix of group talk: An empirical method of analysis and validation. Small Group Behavior, 2, 419-443.

Haskell, R. E. (1978). An analogic model of small group behavior. International Journal of Group Psychotherapy, 28, 27-54.

Hatta, T. (1977). Recognition of Japanese Kanji in the left and right visual fields. Neuropsychologia, 15, 685-688.

Hatta, T., Honjoh, Y, and Mito, H. (1983). Event-related potentials and reaction times as measures of hemispheric differences for physical and semantic Kanji matching. Cortex, 19, 517-528.

Havelock , E. (1983). The linguistic task of the Presocratics: Ionian science in search of an abstract vocabulary. In Robb, K. (Ed.), Language and thought in early greek philosophy. La Salle, IL: Monist Library of Philosophy/The Hegeler Institute.

Havelock, E. (1983). The muse learns to write. New Haven,Conn: Yale University Press.

Havelock, Eric (1963). Preface to Plato. Cambridge, MA: Harvard University Press.

Heilman, K. M., Howell, G., Valenstein, E. and Rothi, L. (1980). Mirror-reading and

writing in association with right-left spatial disorientation . Journal of Neurology, Neurosurgery and Psychiatry, 43, 774-780.

Herman, L. M., (1980). Cognitive characteristics of dolphins. In L. M. Herman, (Ed.), Cetacean behavior: mechanisms and functions, (pp. 363-429), New York: Wiley.

Hilgard, E. R., (1977). Divided consciousness: Multiple controls in human thought and action, New York: Wiley Interscience.

Honeck R. P. and Hoffman, R. R. (Eds.), (1980). Cognition and figurative language. Hillsdale, New Jersey: Lawrence Erlbaum.

Jaynes, J. (1976a). The origin of consciousness in the breakdown of the bicameral mind.

Boston: Houghton Mifflin.

Jaynes, J. (1976b). The evolution of language in the late pleistocene. Annals of the New York Academy of Sciences, 280 ,312-325.

Johnson, M. (1987). The body in the mind. The bodily basis of meaning, imagination, and reason. Chicago, 111: University of Chicago Press.

Johnson, M. G.; Malgady, R. G. (1980). Toward a perceptual theory of metaphoric comprehension. In R. P. Honeck, and Hoffman, R. R. (eds.), Cognition and Figurative Language. Hillsadle, New Jersey: Erlbaum.

Keil, F. C. (1986). Conceptual domains and the acquisition of metaphor. Cognitive Development, 1, 73-96.

Kimura, D. (1966). Dual function asymmetry of the brain in visual perception, Neuropsychologia, 4, 275-285.

Kimura, D and Archibald, Y.(1974). Motor functions of the left hemisphere, Brain, 97. 1974, 337-350. 
Kimura, D. (1967). Functional asymmetry of the brain in dichotic listening. Cortex, 3, 163178.

Kinsbourne, M., and Lempert, H. (1979). Does left brain lateralization of speech arise from right-biased orienting to salient percepts? Human development, 22, 270-275.

Kissin, B. (1986). Conscious and unconscious programs in the brain. (Psychobiology of Human Behavior, Vol. I). New York: Plenum Press.

Kosslyn, S. M and Koenig, O. (1995). Wet Mind: The New Cognitive Neuroscience. New York: The Free Press.

Krashen, S. D. (1975). The major hemisphere. UCLA Educator, 17, (2), 1724.

Krashen, S. (1973). Lateralization, language learning, and the critical periodaome new evidence. Language Learning, 23, 63-74.

Kuhn, T. (1970). The structure ofscientic revolutions. Chicago, IlhUniversity of Chicago Press. Lakoff, G. (1987). Women, fire, and dangerous things: What categories reveal about the mind. Chicago, III: University of Chicago Press.

Lakoff, G, and Johnson, M. (1980). Metaphors we live by. Chicago, 111: University of Chicago Press.

Larsen, B., Skinhoj, B., and Lassen, N. (1979). Cortical activity of left and right hemisphere provoked by reading and visual naming. A rCBF study. Acta Neurologia Scandinavia [Suppl.]. 72, 6-7.

Leary D. (Ed.). (1994). Metaphors in the history of psychology. New York: Cambridge University Press.

LeDoux, J. (1996). The emotional brain. New York: Simon and Schuster.

Levi-Strauss, C. (1966). The savage mind. Chicago, 111: University of Chicago Press. Luria, A. R. (1976). Cognitive development: Its cultural and social foundations.

Cambridge, MA: Harvard University Press.

MacCormac, E, R. (19 85). A cognitive theory of metaphor. Cambridege, MA. MIT Press.

Machinist, P. (1986). On self consciousness in Mesopotamia. In S. N. Eisenstadt. (Ed.),

The origins and diversity of axial age civilizations. New York: SUNY Press.

Marks, L. E. and Bornstein, M. H. (1987). Sensory similarities: Classes characteristics and cognitive consequences. In Haskell, R.E. (Ed.), Cognition and symbolic structures. Norwood, NJ: Ablex.

Marsolek, C. J., Kosslyn, S. M., and Squire, L. R. (1992). Form-specific priming in the right cerebral hemisphere. Journal of Experimental Psychology: Learning, Memory, and Cognition, 18, 492-508.

McIntyre R., C., Pritchard, P. B. and Lombroso, C. T. (1976). Left and right temporal lobe epileptics: A controlled investigation of some psychological differences. Epileseia, 17, 377-386.

Metcalfe, J., Funnell, M., and Gazzaniga., M. S. (1995). Right-hemisphere memory superiority: Studies of a split brain patient. Psychological Science, 6, 167-163.

Mukhametov, L. (1988). The absence of paradoxical sleep in dolphins. In W. P. Koelia, Obal, F. Schulz, H. and Visser P.(Eds.), Sleep'86. Stuttgart and New York: Gustav Fischer Verlag 
Nebes, R. D. (1975). Man's So-Called 'Minor’ Hemisphere. UCLA Edlcator, 17, (2), 13-17. Noble, I. (1966). Mirror-images and the forebrain commissures of the monkey. Nature, 211, 1263-1265.

Ong, W. J. (1982). Orality and literacy. New York: Routledge.

Ornstein, R. (1997). The Right Mind: Making sense of the hemispheres. New York: Harcourt, Brace.

Orton, S. T. (1928) Specific reading disability - strephosymbolia. Journal of the American Medical Association, 90, 1095-9.

Ortony, A. (Ed.), (1979). Metaphor and thought. Cambridge, England: Cambridge University Press.

Osborn, M. (1967).The evaluation of the theory of metaphor in rhetoric. Western Speech, 31, 126.

Owen, A. R. G. (1971). Hysteria, hypnosis, and healing: The work ofj.m. charcot. New York, Garret Pub.

Parry, A. (1971 ). Introduction. In The making ofhomeric verse. The collected papers of Millman Parry, (Ed), New York: Oxford University Press.

Parry, M. (1971 a). The making of Homeric verse. The collected papers of Millman Parry. Adam Parry, (Ed), New York: Oxford University Press.

Parry, M. (1971b). The homeric metaphor as a traditional poetic device. In The making of homeric verse. The collected papers of Millman Parry. Adam Parry, (Ed), New York: Oxford University Press.

Parry, M. (1971 c). The traditional metaphor in homer. In The making ofhomeric verse. The collected papers of Millman Parry. Adam Parry, (Ed), New York: Oxford University Press.

Pinker, S. (1997). How the mind works. New York: W. W. Norton.

Pollio, H. R. Smith, M. K., and Pollio, M. R. (1990). Figurative language and cognitive psychology. Language and ????

Reinsch, L. (1971). An investigation of the effects of the metaphor and simile in persuasive discourse. Speech Monographs, 38, 142-145. Renfrew, C. and Zubrow, E. B. W. (Eds.), (1996). The ancient mind: Elements of cognitive archeology. New York: Cambridge University Press.

Richards, I. A., (1936). The philosophy of rhetoric. London.'Oxford University Press.

Ricoeur, P. (1975). The rule of metaphor. Toronto: University of Toronto Press.

Robb, K. (Ed.), (1983). Language and thought in early greek philosophy. La Salle, IL:

Monist Library of Philosophy/The Hegeler Institute.

Rousseau, J. J. (1966). Essay on the origin of language, J. H. Moran and A. Goode (trans.). Chicago: University of Chicago Press.

Sasanuma, S. (1975). Kane and Kanji rocessing in Japanese aphasics. Brain and Language, 2, 369-383.

Schott, G. D. (1980). Mirror movements of the left arm following peripheral damage to the preferred right arm. Journal of Neurology, Neurosurgery and Psychiatry, 43, 768-773.

Shanon. B. (1988). On the similarity of features. New Ideas in Psychology, 6, 307-321. Shibles, W. (1971). Analysis of metaphor in the light of W M. Urban's theories. The

Hague: Mouton. 
Silverberg, R T, Gordon, N., W., Pollack, S. and Bentin, S. (1980). Shift of visual field preference for Hebrew words in native speakers learning to read. Brain and Language, 11, 99-101.

Simon, H. (1994). Literary Criticism: A Cognitive Approach. In: Stanford Humanities Review, 4, \# 1 (Special issue) Franchi, S. and Giizeldere, G. (Eds.), Bridging the Gap: Where Cognitive Science Meets Literary Criticism (For online version see, http: //shr. Stanford, edu/shreview/4-1/text/toc.html)

Sirat, C. (1988). The material conditions of the lateralization of the Ductus. In D. de Kerckhove and C. J. Lumsden, (Eds.), (pp. 173-201). The alphabet and the brain: The lateralization of writing. Berlin: Springer-Verlag.

Skoyles. J. R. (1988). Right Hemisphere Literacy in the Ancient World. In D. de Kerckhove and Lumsden, C. J. (Eds.), (pp. 363-380). The alphabet and the brain: The lateralization of writing. Berlin: Springer-Verlag.

Skoyles, J. R (1984). Alphabet and the western mind. Nature, 309, 409^110.

Snell, B. (1960). The discovery of the mind: The Greek origins of European thought.

New York: Harper Books.

Snow, C. P. and Collini, S. (1999). The Two Cultures. Cambridge University Press. Springer, S. P. and Deutsch, G. (1981). Left brain, right brain. San Francisco: W. H.

Freeman.

Thorndyke, P. W. (1977). Cognitive structures in comprehension and memory of narrative discourse. Cognitive Psychology, 9, 77-110.

Trabant, J.( 1991). Parlare cantando: language singing in vico and herder. New Vico Studies, 9 , $1-16$.

Turbayne, C. (1963). The Myth of Metaphor. New Haven: Yale University Press. Tzavaras, A., Kaprinis, G., and Gatzoya (1981). A Literacy and hemispheric specialization for language: Digit dichotic listening in illiterates. Neuropsychologia ,19, 565-570.

Tzavaras, A, Phocas, C, Kaprinis, G, and Karavatos, A. (1993). A Literacy and hemispheric specialization for language: Dichotic listening in young functionally illiterate men. Perceptual and Motor Skills, 77, 195-199.

Vico, G. (1948). The new science. (T.G. Bergin and M.H. Fisch, trans.) Ithaca, NY: Cornell University Press.

Wada, J. and Rasmussen, T, (1960). Intracarotid Injection of Sodium Amytal for the lateralization of cerebral speech dominance. Journal of Neurosurgery, 17, 266-282.

Wapner, W., Hamby, S., and Gardner, H. (1981 ). The role of the right hemisphere in the apprehension of complex linguistic materials. Brain and Language, 14, 15-33.

Weiskrantz, L. (1986). Blindsight. A case history and implications. New York: Oxford University Press.

Wheelright, P. (1962). Metaphor and reality. Bloomington, IN: Indiana University Press. Winner, E. and Gardner, H. (1977). The Comprehension of Metaphor in brain-damaged patients. Brain, 100, 717-729.

Witelson, S. F. and Kigar, D. L. (1988). Anatomical development of the corpus callosum in humans: A review with reference to sex and cognition. In D.L. Molfese, and S. J.

Segalowitz (Eds.), Brain lateralization in children. New York Guilford Press.

Witelson, S. F, and Kristofferson, A. B. (Eds.), (1986). Symposium on consciousness.

Canadian Psvchologv. (2). 122-182. 
Zaidel, D. W.(1994). Worlds apart: Pictorial semantics in the left and right cerebral hemispheres. Current Directions in Psychological Science, 3, 5-8.

Zaidel, E. (1982). Reading by the disconnected right hemisphere: An aphasiological perspective. In Y. Zotterman (Ed.), Dyslexia: Neurological, cognitive, and/linguistic aspects.

Wenner-Glen Symposium Series, Vol. 35 Oxford: Pergamon Press.

Zaidel, E. and Peters, A. M. (1981). Phonological encoding and ideographic reading by the disconnected right hemisphere: Two case studies. Brain and Language 14, 205- -234.

Zook J. A. and J. H. Dwyer. (1976). Cultural differences in hemisphericity: A critique. Bulletin of the Los Angeles Neurological Societies, 41, 87-90. 